\title{
Neural markers of errors as endophenotypes in neuropsychiatric disorders
}

\author{
Dara S. Manoach ${ }^{1,2 *}$ and Yigal Agam ${ }^{1,2}$ \\ ' Department of Psychiatry, Massachusetts General Hospital and Harvard Medical School, Boston, MA, USA \\ 2 Athinoula A. Martinos Center for Biomedical Imaging, Charlestown, MA, USA
}

\author{
Edited by: \\ Tim Hahn, Universität Würzburg, \\ Germany \\ Reviewed by: \\ Ruthger Righart, Institute for Stroke \\ and Dementia Research, Germany \\ Stefano Sandrone, Institute of \\ Neuroinformatics, Switzerland \\ *Correspondence: \\ Dara S. Manoach, Massachusetts \\ General Hospital, 149 13th St., \\ Room 1.111, Charlestown, MA \\ 02129, USA \\ e-mail:dara@nmr.mgh.harvard.edu
}

Learning from errors is fundamental to adaptive human behavior. It requires detecting errors, evaluating what went wrong, and adjusting behavior accordingly. These dynamic adjustments are at the heart of behavioral flexibility and accumulating evidence suggests that deficient error processing contributes to maladaptively rigid and repetitive behavior in a range of neuropsychiatric disorders. Neuroimaging and electrophysiological studies reveal highly reliable neural markers of error processing. In this review, we evaluate the evidence that abnormalities in these neural markers can serve as sensitive endophenotypes of neuropsychiatric disorders. We describe the behavioral and neural hallmarks of error processing, their mediation by common genetic polymorphisms, and impairments in schizophrenia, obsessive-compulsive disorder, and autism spectrum disorders. We conclude that neural markers of errors meet several important criteria as endophenotypes including heritability, established neuroanatomical and neurochemical substrates, association with neuropsychiatric disorders, presence in syndromallyunaffected family members, and evidence of genetic mediation. Understanding the mechanisms of error processing deficits in neuropsychiatric disorders may provide novel neural and behavioral targets for treatment and sensitive surrogate markers of treatment response. Treating error processing deficits may improve functional outcome since error signals provide crucial information for flexible adaptation to changing environments. Given the dearth of effective interventions for cognitive deficits in neuropsychiatric disorders, this represents a potentially promising approach.

Keywords: error-related negativity, anterior cingulate, error processing, response monitoring, imaging genetics
To adapt to the environment, human beings must learn from the consequences of their behavior. Understanding the nature of the brain mechanisms that flexibly modify behavior based on its consequences is a fundamental goal of neuroscience. These mechanisms are also of considerable clinical importance since a number of neuropsychiatric disorders are strongly associated with maladaptively rigid and repetitive behaviors that are not optimally responsive to outcomes. One approach to understanding the neural basis of learning from consequences is to study error processing. Errors provide critical information for adjusting behavior to optimize outcomes. Error processing, which is also referred to as "response monitoring" or "performance monitoring," involves detecting errors during task performance, evaluating what went wrong, and adjusting behavior accordingly. These dynamic adjustments of responses are at the heart of behavioral flexibility. They enable individuals to optimize function in complex, uncertain, and constantly changing environments. Since learning from errors is impaired in several neuropsychiatric disorders, understanding the neural and genetic mechanisms of error processing has important clinical implications. Identifying specific deficits can illuminate the pathophysiology of these disorders and provide novel targets for treatment. Below, we selectively review the behavioral and neural hallmarks of error processing; impairments in schizophrenia, obsessive-compulsive disorder, and autism spectrum disorders (ASDs); and genetic contributions. The goal is to evaluate the potential of the neural markers of errors to serve as endophenotypes. Endophenotypes are biologically-based heritable dysfunctions that are thought to be a closer reflection of the effects of the genes that predispose to illness than either the diagnosis itself, or the symptoms that define it (Gottesman and Gould, 2003). The identification of clinically-relevant endophenotypes can facilitate the discovery of susceptibility genes, mechanisms of illness, and targets for intervention (Hariri et al., 2006).

\section{BEHAVIORAL INDICES OF ERROR PROCESSING}

Both the behavioral and neural markers of error processing are considered to be "generic" in that they are elicited by a wide range of tasks regardless of response modality (Holroyd and Coles, 2002). Many experimental tasks used to study error processing in humans require response inhibition, or the suppression of prepotent but contextually inappropriate responses. These include variations of go no-go, antisaccade (Hallett, 1978), countermanding or stop-signal (Logan and Cowan, 1984), Stroop (1935), Simon (1969), and perhaps most commonly, Eriksen flanker (Eriksen and Eriksen, 1974) tasks. 
Errors give rise to both immediate and longer-term remedial adjustments of behavior. Short-term, or trial-by-trial adjustments include the immediate self-correction of errors and the slowing of reaction time (RT) in trials that follow an error (i.e., post-error slowing) (Rabbitt, 1966). These trial-by-trail adjustments of RT based on error history are well-described by the Speed-Accuracy Trade-Off (SATO) function. The SATO function depicts the non-linear relation between speed and accuracy such that faster responding does not affect accuracy, but only up to a point. Beyond that point, speed and accuracy are inversely related, with slower responses having a greater probability of being correct (Figure 1A). This transition point can be regarded as an optimum, where the best accuracy is achieved at the fastest possible speed. Over trials, responses speed up until an error is committed (Ridderinkhof et al., 2003), and following an error, RT slows, and the probability of an error decreases (Figure 1B). This pattern can be interpreted as a progression to riskier positions on the SATO function culminating in an error. The error is followed by a shift back to a safer position on the function that has a greater likelihood of a correct response.

Reinforcement learning theory (Thorndike, 1911) can be invoked to account for longer-term behavioral changes in response to errors. Its main principle is that rewarded actions are more likely to be repeated, while actions with negative consequences are less likely to recur. In behavioral terms, reinforcement learning involves the strengthening or weakening of stimulus-response mappings based on behavioral outcomes. While reinforcement learning has traditionally been studied using explicit rewards and punishments, more recent theory extends it to errors (Holroyd and Coles, 2002). Errors on cognitive tasks are both salient (in that they are often unexpected) and aversive (representing the non-achievement of a goal). As failures of performance they often have negative consequences. For these reasons, errors prompt reinforcement learning.

\section{NEURAL MARKERS OF ERRORS, THEIR FUNCTIONAL SIGNIFICANCE AND RELATIONS TO ONE ANOTHER}

Electrophysiological and neuroimaging studies have identified two highly reliable neural markers of error commission-the error-related negativity (ERN) and functional MRI (fMRI) activation of the dorsal anterior cingulate cortex (dACC; Taylor et al., 2007) — that are the focus of the present review. Although these error markers have been extensively studied, their functional significance and relations to one another are incompletely understood.

\section{THE ERROR-RELATED NEGATIVITY (ERN)}

The ERN or error negativity $(\mathrm{Ne})$ is an event-related potential that peaks $\sim 100 \mathrm{~ms}$ following an error (Figure 2, Falkenstein et al., 1991; Gehring et al., 1993; Dehaene et al., 1994; Van Veen and Carter, 2002) and is usually measured on the scalp with electroencephalograpy (EEG), magnetoencephalography (MEG; Keil et al., 2010) or a combination of both techniques (Agam et al., 2011). The ERN is usually defined as the peak of the difference between the averaged waveforms of error and correct trials time-locked to the onset of the response. The ERN is the earliest error marker and is "generic" in that it is seen across a variety of behavioral paradigms and response modalities. Comparisons of ERNs time-locked to button presses, saccadic eye movements, or foot presses, reveal a similar morphology, amplitude and scalp topography (Holroyd et al., 1998; Van 'T Ent and Apkarian, 1999). ERN latency, however, varies based on the measurement technique. Button presses elicit shorter latencies than ERNs locked to the electromyography (EMG) or saccadic responses as measured by electrooculography (EOG). This reflects that EMG and EOG measure the onset of movement, which occurs earlier than its outcome (e.g., a button press). The ERN is usually maximal at electrode $\mathrm{Cz}$ on the scalp (e.g., Van Veen and Carter, 2002; Van Schie et al., 2004; Agam et al., 2011), but the peak location can be more anterior (e.g., Gehring and Fencsik, 2001; Nieuwenhuis et al., 2003; Endrass et al., 2005) or posterior (e.g.,

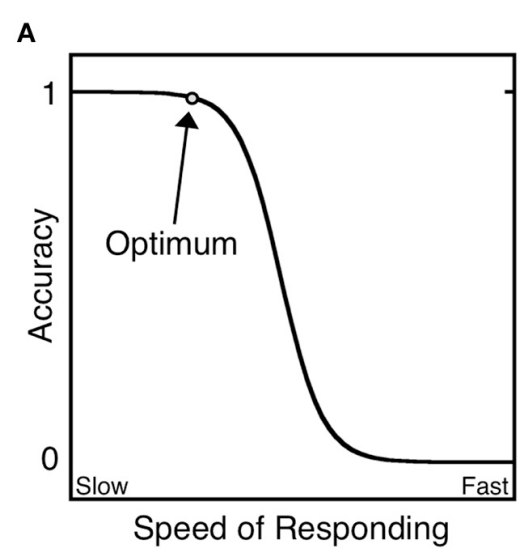

FIGURE 1 | Trial-by-trial adjustments of reaction time (RT). (A) A schematic depiction of the SATO function. The circle denotes the optimum: the point at which the highest accuracy is achieved at the fastest possible speed. Beyond this point, speedier responses entail a cost (trade-off) in reduced accuracy. (B)

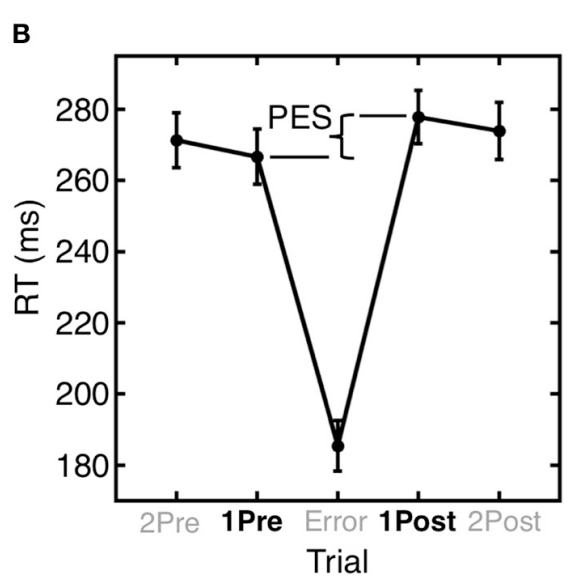

Mean saccadic RT during an antisaccade task as a function of trial position relative to an error trial. Post-error slowing (PES) is defined as the difference in RT between the trial following the error (1Post) and the trial preceding the error (1Pre). Error bars represent the standard error of the mean. 


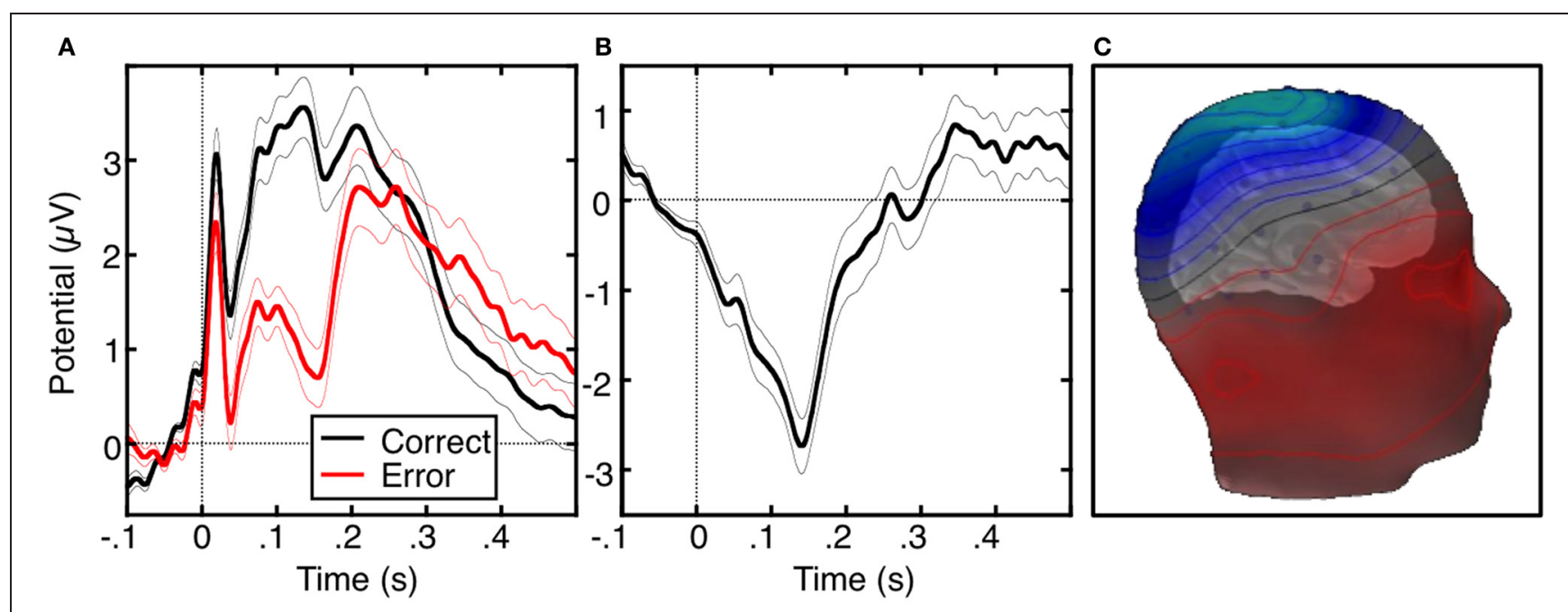

FIGURE 2 | The error-related negativity (ERN). (A) Grand average waveforms for correct (black) and error (red) antisaccade trials, time-locked to the onset of the saccade. (B) Difference waveform, obtained by subtracting the correct waveform from the error waveform. (C) Scalp distribution of the ERN, displayed on a template head model. Adapted from Agam et al. (2011).
Hajcak et al., 2004, Van Boxtel et al., 2005; Ladouceur et al., 2007) and factors such as response modality and task fail to provide a convincing account of this variability.

The ERN has been proposed to reflect error detection and reinforcement learning (Paus et al., 1993; Holroyd and Coles, 2002; Holroyd et al., 2004b). Its amplitude is greater when accuracy is emphasized over speed (Gehring et al., 1993), when errors are corrected (Scheffers and Coles, 2000), when errors incur greater loss (Holroyd et al., 2004a) and when errors are less frequent and therefore also less expected (Gehring et al., 1993; Hajcak et al., 2003). Larger ERNs are associated with greater post-error slowing of responses (Debener et al., 2005) and ERN latency predicts the speed of self-corrections (Fiehler et al., 2005). These findings suggest that the ERN indicates error detection, is sensitive to both the predictability and value of outcomes, and contributes to dynamic, trial-by-trial adjustments of performance.

\section{ERROR POSITIVITY (Pe)}

A second EEG error marker warrants consideration given its relevance to neuropsychiatric disorders. The error positivity or Pe (Van Veen and Carter, 2002) is an event-related potential that occurs 300-500 ms following an error (for review see, Overbeek et al., 2005). The Pe has been localized to the rostral anterior cingulate cortex (Van Veen and Carter, 2002; Van Boxtel et al., 2005), though one study reported a dACC source (Herrmann et al., 2004). The Pe is not as well characterized and is less consistently observed than the ERN, which may reflect that it is a later and more variable component of error processing. While the ERN is present regardless of whether an error was perceived, the Pe is present only for perceived errors and is thought to index error awareness (Nieuwenhuis et al., 2001; Endrass et al., 2007). The Pe has also been associated with the subjective or emotional appraisal of errors (Van Veen and Carter, 2002) and with short-term performance adjustments such as error correction and post-error slowing (Nieuwenhuis et al., 2001).

\section{ERROR-RELATED FMRI ACTIVATION OF THE ANTERIOR CINGULATE CORTEX (ACC)}

Error commission is also reliably associated with increased fMRI activation of the ACC on error compared with correct trials (i.e., error-related activation, Figure 3; for review see, Taylor et al., 2007). The ACC can be divided into a dorsal region (dACC) that extends caudally from the genu of the corpus callosum to the vertical plane of the anterior commissure, and interacts with the striatum and other cortical regions to mediate motor and cognitive processing, and a rostral region (rACC) that lies anterior and ventral to the genu of the corpus callosum and interacts with other paralimbic and limbic regions, including the amygdala and insula, to mediate emotional processing (Devinsky et al., 1995; Bush et al., 1998, 2000; Whalen et al., 1998; Phillips et al., 2003). Like the Pe, error-related rACC activation is thought to reflect appraisal of the affective or motivational significance of errors (Van Veen and Carter, 2002; Luu et al., 2003; Taylor et al., 2006). Such appraisal may also involve the insula and amygdala, both of which are densely interconnected with the rACC (Van Hoesen et al., 1993) and show increased activity with errors (Menon et al., 2001; Brazdil et al., 2002; Garavan et al., 2002; Polli et al., 2009). While both dACC and rACC show error-related activation (Van Veen and Carter, 2002; Luu et al., 2003; Taylor et al., 2006), dACC activation is more consistently observed. Like the ERN, greater error-related AACC activation is associated with lower error rates (Polli et al., 2008; Fitzgerald et al., 2010) and increased posterror slowing (Garavan et al., 2002; Kerns et al., 2004; Klein et al., 2007a).

\section{MODULATION OF DEFAULT NETWORK ACTIVATION IN RELATION TO ERRORS}

The brain's default network is thought to mediate self-referential and affective processing and is usually deactivated during effortful cognitive tasks (Raichle et al., 2001; Buckner et al., 2008). During error trials (Polli et al., 2005) and trials immediately preceding 


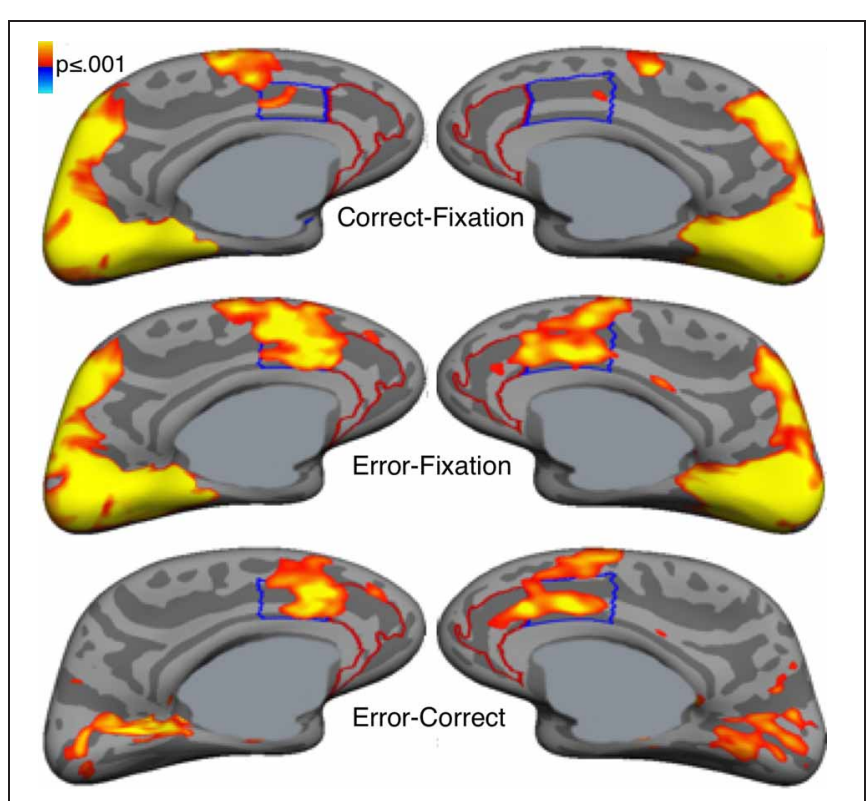

FIGURE 3 | Error-related activation in the anterior cingulate cortex (ACC). Statistical maps, displayed on medial cortical surface templates, show activation on correct trials vs. a fixation baseline (top), error vs. fixation (middle) and error vs. correct (bottom). Gray masks cover subcortical regions in which activation is displaced in a surface rendering. The AACC and rACC are outlined in blue and red, respectively. Adapted from Polli et al. (2005).

errors (Li et al., 2007; Eichele et al., 2008), however, the default network shows relatively increased activation, which may reflect increased focus on the internal milieu at the expense of attention to the task (Drevets and Raichle, 1998). In trials that follow errors, task-induced deactivation is re-established (Eichele et al., 2008). This cyclical pattern of default network activation in trials including and surrounding errors correlates with SATO based changes in RT (i.e., pre-error speeding, faster errors, and posterror slowing, Agam et al., 2013) and suggests that interference from internally-directed thought culminates in an error, which, in turn prompts renewed attention to the task in the subsequent trial. These changes in activation are not strictly error markers (i.e., they are not specific to errors nor do they necessarily indicate that an error has occurred), but they may contribute to error commission and to behavioral adjustments following errors such as post-error slowing. Several reviews have addressed the role of default network function in neuropsychiatric disorders (e.g., Buckner et al., 2008; Broyd et al., 2009; Sandrone, 2012; Whitfield-Gabrieli and Ford, 2012). Whether changes of default network activity in relation to errors are affected in neuropsychiatric disorders, however, is largely unexplored.

\section{ERROR-BASED REINFORCEMENT LEARNING}

Error-related dACC activation is often assumed to be the hemodynamic correlate of the ERN. This assumption is consistent with both EEG and MEG studies that have reported a dACC source for the ERN and with models that attribute both error markers to a specific neural mechanism that implements error-based reinforcement learning (Holroyd and Coles, 2002; Ridderinkhof et al., 2004; Taylor et al., 2007). Consistent with animal neurophysiology and human neuroimaging findings, these models view the neural sequelae of error commission as indices of errorbased reinforcement learning (Holroyd and Coles, 2002; Schultz, 2002). When an error occurs, the striatum detects a mismatch between the intended (correct) versus actual (error) outcome. This mismatch or "prediction error" results in a phasic decrease in mesencephalic dopamine (DA) release that results in the disinhibition of neurons in the dACC. These neurons generate the ERN. According to this theory, both increased dACC activation and the ERN reflect the use of DA-dependent error signals to modify the associative strength of stimulus-response mappings in the service of optimizing behavioral outcomes (Holroyd et al., 2003, 2004b). Thus, both error-related dACC activation and ERN can be conceptualized as DA-dependent training signals that are used to learn from errors (Holroyd and Coles, 2002; Brown and Braver, 2005). Similar neural mechanisms of error processing have been observed across species for a variety of learning tasks. For example, the songbird uses input from a basal ganglia - thalamocortical circuit to recognize and correct vocal errors while learning its distinctive song (Andalman and Fee, 2009). Such findings suggest that this neural circuitry represents an evolutionarily conserved mechanism for learning from errors.

\section{RELATION OF THE ERN TO dACC ACTIVATION}

Despite the many studies that report a dACC source for the ERN, the location of the neural generator of the ERN is still a topic of debate. When compared across studies, the dACC source loci of the ERN show considerable variation (for review, see Agam et al., 2011) and all are posterior to the mean location of error-related fMRI activation (based on a meta-analysis of 13 fMRI studies, Ridderinkhof et al., 2004). Some ERN loci also fall in the posterior cingulate cortex (PCC) according to standard anatomical definitions that place the ACC/PCC border between $y=-2$ and $y=$ $-12 \mathrm{~mm}$ in Talairach space (Bush et al., 2000). The PCC is also a plausible generator of the ERN. It shows error-related fMRI activation (Menon et al., 2001; Fassbender et al., 2004; Wittfoth et al., 2008), though not nearly as consistently as the dACC, and like the ERN, its activity is modulated by the value of behavioral outcomes (McCoy et al., 2003; Fujiwara et al., 2009; Smith et al., 2009). An MEG study reported a PCC source for the feedback-related negativity, which is thought to be generated by the same generic mechanism as the ERN (Donamayor et al., 2011). Further, a study from Agam and colleagues that combined data from EEG and MEG, localized the source of the ERN to the PCC (Agam et al., 2011). This PCC region was clearly distinct from error-related dACC activation measured in the same participants performing the same task during fMRI.

These findings challenge the view that dACC activation and the ERN are different measurements of the same underlying neural mechanism. Instead, they indicate that the ERN and fMRI activation of the dACC reflect distinct neural responses to errors. In the combined MEG/EEG, fMRI, and diffusion tensor imaging (DTI) study of Agam and colleagues, ERN amplitude correlated with fMRI activation in both the PCC and AACC, and these two regions showed coordinated activity based on functional 
connectivity MRI. This suggests that the dACC and PCC are components of a functional network that mediates error processing. The PCC and ACC have direct anatomical connections through the cingulum bundle (Schmahmann et al., 2007) and increased microstructural integrity of the posterior cingulum bundle (as indexed by DTI measurements of fractional anisotropy) predicted faster error self-correction. To the degree that fractional anisotropy reflects myelination, increased myelination along the cingulum bundle may speed the conduction of the message that an error has occurred thereby resulting in faster corrective responses. Taken together, these findings are consistent with the theory that the PCC detects errors, gives rise to the ERN, and then relays error information to the dACC via the cingulum bundle to implement corrective behavior. Refinements of this working model will likely follow given that the mechanisms of error processing remain a highly active area of research.

\section{ERROR PROCESSING IMPAIRMENTS IN NEUROPSYCHIATRIC DISORDERS}

Although the present review focuses on schizophrenia, obsessivecompulsive disorder (OCD) and ASD, accumulating evidence suggests that error processing deficits contribute to rigid, repetitive behavior in a range of disorders. For example, a previous review described ERN abnormalities in anxiety disorders, depression and substance abuse and their relations to symptoms (Olvet and Hajcak, 2008). Emerging evidence also indicates that error processing deficits differ by diagnosis suggesting distinct neural mechanisms and genetic contributions. This has important implications for understanding pathophysiology and for the treatment of associated cognitive and behavioral dysfunction. Below, we evaluate evidence that neuroimaging-based markers of deficient error processing can serve as sensitive endophenotypes of neuropsychiatric disorders.

\section{SCHIZOPHRENIA}

Perseveration, or the contextually inappropriate and unintentional repetition of responses, is a classic behavioral abnormality in schizophrenia. At least some forms of perseveration may reflect a failure to use error feedback to guide behavior. A classic example is continuing to make a previously reinforced response on the Wisconsin Card Sort Test even though feedback indicates that it is no longer correct (e.g., Goldberg et al., 1987). These perseverative errors reflect both motivational and cognitive factors (Summerfelt et al., 1991) and exemplify the behavioral rigidity despite changing contingencies that is often observed in schizophrenia.

Both neuroimaging and electrophysiological studies consistently report blunted neural responses to errors in schizophrenia. fMRI studies show reduced error-related dACC and rACC activation (Carter et al., 2001; Laurens et al., 2003; Kerns et al., 2005). Reduced error-related activation extends to "reinforcement learning circuitry," comprising the dACC, substantia nigra, caudate, and putamen, and to "affective appraisal circuitry" comprising the rACC, insula, and amygdala, in which reduced activation may reflect diminished concern regarding behavioral outcomes (Polli et al., 2008). These reductions remain after statistically controlling for the effects of antipsychotic medication dose and error rate, the latter indicating that the blunted neural response to errors in schizophrenia is not simply a reflection of more frequent, and therefore more predictable errors.

Patients with schizophrenia also consistently show a blunted ERN (Kopp and Rist, 1999; Alain et al., 2002; Bates et al., 2002; Mathalon et al., 2002; Morris et al., 2006; Foti et al., 2012; Perez et al., 2012). Even in the context of an abnormal ERN, however, the Pe is intact in patients in many (Alain et al., 2002; Mathalon et al., 2002; Morris et al., 2006; Simmonite et al., 2012) but not all studies (Foti et al., 2012; Perez et al., 2012). Immediate errorrelated performance adjustments such as post-error slowing and error self-correction are also often intact (Kopp and Rist, 1994, 1999; Levy et al., 1998; Mathalon et al., 2002; Laurens et al., 2003; Polli et al., 2006, 2008), although impaired performance adjustments have also been reported (Malenka et al., 1982, 1986; Carter et al., 2001; Turken et al., 2003). Dissociations between intact performance adjustments and reduced ACC activity and ERN amplitude are often seen within single studies (Kopp and Rist, 1999; Mathalon et al., 2002; Laurens et al., 2003; Polli et al., 2008) and suggest that error processing deficits in schizophrenia are selective.

Findings of blunted ERN and dACC activation in schizophrenia are remarkably consistent and may reflect a more general problem with reinforcement learning, which is impaired in schizophrenia (Waltz and Gold, 2007; Waltz et al., 2007, 2010). They may also reflect functional and structural abnormalities of the cingulate cortex. There is overwhelming evidence of abnormal ACC function and structure in schizophrenia including gray matter abnormalities (e.g., Ohnuma et al., 1997; Goldstein et al., 1999; Sigmundsson et al., 2001; Suzuki et al., 2002; Kuperberg et al., 2003; Ha et al., 2004; Yamasue et al., 2004; Mitelman et al., 2005), volume reductions in the white matter underlying the ACC (McDonald et al., 2005; Mitelman et al., 2005) and reduced fractional anisotropy of white matter underlying the cingulate cortex in many (Ardekani et al., 2003; Kubicki et al., 2003; Sun et al., 2003; Wang et al., 2004; Hao et al., 2006; Manoach et al., 2007) but not all studies (Buchsbaum et al., 1998; Agartz et al., 2001; Foong et al., 2002; Burns et al., 2003). Histopathological studies give evidence of disturbances in ACC micro- and macro-circuitry that might alter communication with connected regions (e.g., Benes, 1993, 2000), consistent with reports of reduced functional and structural connectivity of the ACC in schizophrenia (e.g., Manoach et al., 2007; Tu et al., 2010; Kyriakopoulos et al., 2012; Yan et al., 2012).

Treatment with antipsychotic drugs is an important confound in this literature given its effects on dopamine neurotransmission and indices of error processing (e.g., Zirnheld et al., 2004). Several lines of evidence suggest that deficient error processing is not merely a side-effect of treatment. Functional and structural ACC abnormalities, which predict the onset of psychosis (Fornito et al., 2008), are seen in never-medicated high-risk youth (Whalley et al., 2006), and in never-medicated children experiencing psychotic symptoms (Jacobson et al., 2010). In addition, a blunted ERN, similar to that observed in schizophrenia, is seen in syndromally-unaffected siblings (Simmonite et al., 2012), in never-medicated children with putative antecedents to schizophrenia (Laurens et al., 2010) and in antipsychotic 
naïve patients at high clinical risk for psychosis (Perez et al., 2012). These studies suggest that antipsychotic drugs do not fully account for blunted error processing or functional and structural ACC abnormalities in schizophrenia. Instead, this literature suggests that ACC abnormalities and error processing deficits are trait markers of genetic vulnerability to schizophrenia that predate the onset of illness. Impairments in evaluating and learning from errors in schizophrenia may substantially contribute to the rigid, perseverative, and maladaptive patterns of thought and behavior that characterize schizophrenia and compromise social and occupational function (Kim et al., 2006). In support of this possibility, a recent study reported that a blunted ERN was associated with more severe negative symptoms and poorer real world function as indicated by unemployment and re-hospitalization (Foti et al., 2012).

\section{OBSESSIVE-COMPULSIVE DISORDER (OCD)}

OCD is characterized by uncontrollable, unwanted thoughts (i.e., obsessions) and repetitive, ritualized behaviors that individuals feel compelled to perform (compulsions). In contrast to the blunted neural responses to errors in schizophrenia, OCD is often associated with exaggerated error responses including increased error-related ACC activation (Ursu et al., 2003; Fitzgerald et al., 2005, 2010; Maltby et al., 2005) and increased ERN amplitude not only on error trials (Gehring et al., 2000; Johannes et al., 2001; Ruchsow et al., 2005; Santesso et al., 2006; Endrass et al., 2008, 2010; Xiao et al., 2011) but also on correct trials in some (Ursu et al., 2003; Maltby et al., 2005), but not all studies (Gehring et al., 2000; Fitzgerald et al., 2005). One study reported a normal ERN to errors in OCD (e.g., Nieuwenhuis et al., 2005) and recent findings (Kaczkurkin, 2013) including those of a metaanalysis (Mathews et al., 2012) suggest that while the ERN is generally increased, this varies based on the type of task, the level of difficulty and the symptoms present. A recent study of children with OCD found an increased ERN in both patients and their unaffected siblings relative to controls suggesting that the ERN is a marker of genetic risk for OCD (Carrasco et al., 2013). Both increased ERN amplitude (Gehring et al., 2000) and error-related ACC activation (Ursu et al., 2003; Fitzgerald et al., 2005) have been associated with the severity of obsessions and compulsions in OCD suggesting that hyperactive error processing contributes to its defining features. This hypothesis is consistent with a longstanding theory of OCD that inappropriate and exaggerated error signals in response to behavioral outcomes lead to a pervasive sense of incompleteness and self-doubt (Pitman, 1987) that triggers the compulsion to repeat behaviors, even if they were already successfully completed (Maltby et al., 2005). In this scenario, an individual suffering from OCD may remember correctly that they locked the door, but inappropriate and persistent error signals may indicate that something is "not quite right" and compel them to check repeatedly that the door is indeed locked. Findings that the ACC and connected regions show increased activation during symptom provocation in OCD (Breiter et al., 1996), and that cingulotomy relieves obsessions and compulsions (Dougherty et al., 2002) also support the link between hyperactivity in ACC circuitry and rigid, repetitive behaviors.
Measurements of obsessive-compulsive behavior have also been related to indices of error processing in non-clinical samples. Obsessive characteristics are related to the amplitudes of the ERN and Pe in children (Santesso et al., 2006) and to the amplitude of the ERN in college undergraduates (Hajcak and Simons, 2002), suggesting that obsessive-compulsive traits in the general population are mediated by error processing mechanisms.

\section{AUTISM SPECTRUM DISORDERS (ASDs)}

ASDs are neurodevelopmental disorders characterized by three core features: impaired social interaction, impaired communication, and restricted, repetitive and stereotyped patterns of behavior, interests and activities. Although repetitive and restricted behaviors are often the most disabling feature of ASD (Bishop et al., 2007) they have received the least research attention. They are present as early as 18 months, predict outcome independently of social and communication deficits, and may interfere with the development of social and communication skills that are deficient in ASD (Morgan et al., 2008; Watt et al., 2008). The hypothesis that error processing deficits characterize ASD and contribute to behavioral repetition and rigidity receives only mixed support from the literature.

Several studies have reported a blunted ERN in ASD (Vlamings et al., 2008; Sokhadze et al., 2010, 2012b; South et al., 2010; Santesso et al., 2011), one has reported normal ERN (Groen et al., 2008), and yet another found an increased latency (and amplitude in a high functioning subset of participants) of the ERN (Henderson et al., 2006). The finding that repetitive low frequency transcranial magnetic stimulation (rTMS) to bilateral dorsolateral prefrontal cortex in high functioning children with ASD was associated with an increased ERN (but also a decreased error rate), suggests the possibility of intervention to modulate error processing (Sokhadze et al., 2012a).

Behaviorally, reduced error self-correction (Russell and Jarrold, 1998), normal rates of error self-correction (Thakkar et al., 2008), and reduced post-error slowing (Bogte et al., 2007) have all been observed. Two fMRI studies reported exaggerated error-related ACC activation in ASD (Thakkar et al., 2008; Goldberg et al., 2011) and in one of these, increased ACC activation on correct trials that correlated with higher clinical ratings of restricted, repetitive behavior in ASD, thus linking abnormal error processing to a core symptom (Thakkar et al., 2008). This relation may reflect that reduced discrimination between correct and error outcomes interferes with adjusting behavior to obtain the most favorable outcome. Another compatible possibility is that like OCD, in ASD uncomfortable error signals following correct responses compel repetitive behavior. In ASD these abnormal signals on correct trials were maximal in the rACC, which is thought to contribute to an appraisal of the affective or motivational salience of errors (Van Veen and Carter, 2002; Luu et al., 2003; Taylor et al., 2006). Finally, three studies, including the one reporting increased ACC activation on both error and correct trials, have reported reduced fractional anisotropy (FA) in ACC white matter as measured by DTI (Barnea-Goraly et al., 2004; Thakkar et al., 2008; Noriuchi et al., 2010), but not a fourth, 
which reported increased FA in ACC white matter (Cheng et al., 2010).

In summary, the literature provides only preliminary support for the hypothesis that cingulate cortex abnormalities impair error processing in ASD and contribute to restricted, repetitive behavior. At present, repetitive behaviors in ASD are incompletely understood and neurobiologically-valid dimensions have not been delineated. Efforts to understand the contribution of error processing to specific dimensions of repetitive behavior and to identify the underlying mechanisms can guide the development of targeted treatments.

\section{RATIONALE FOR THE USE OF NEUROIMAGING-BASED COGNITIVE ENDOPHENOTYPES}

Although Diagnostic and Statistical Manual (DSM) Axis I psychiatric disorders are highly heritable, their genetic origins remain elusive. A major obstacle to identifying genetic risk factors is the difficulty defining neurobiologically-valid phenotypes for inclusion in studies. Current DSM criteria for disorders such as schizophrenia and autism define phenotypes that are so broad that it is possible for two study samples with the same diagnosis to bear little resemblance to one another. This phenotypic heterogeneity suggests etiological and genetic heterogeneity and reliance on such overly broad diagnostic categories can lead to inconsistent findings. Within studies, relatively large effects may be obscured because they only characterize a subset of the sample. While phenotypic heterogeneity is expected within complex genetic disorders such as schizophrenia and autism, subdivision based on phenotypes has not led to neurobiologically-valid subtyping schemes. In schizophrenia, for example, most subtyping schemes have been based on symptoms (e.g., positive vs. negative, deficit vs. non-deficit, paranoid vs. non-paranoid), but symptom definitions are broad and imprecise and their assessment is heavily dependent on self-report. In addition, symptoms often lack temporal stability and predictive validity (i.e., they do not provide an adequate account of variability in other important measures such as brain structure or function, disease course, or functional outcome). Moreover, neither diagnosis nor symptoms can identify syndromally-unaffected relatives who carry susceptibility genes. Finally, the substantial shared genetic liability for neuropsychiatric disorders such as schizophrenia, major depressive disorder, ASD, attention deficit-hyperactivity disorder and bipolar disorder (e.g., Craddock et al., 2006a; Crespi et al., 2010; Purcell et al., 2009; Cross-Disorder Group of the Psychiatric Genomics et al., 2013), reinforces that our present diagnostic categories and symptom definitions do not map onto distinct underlying genetic etiologies. To the extent that genes cause psychiatric disorders and their signs and symptoms, they do so via their effects on brain function (Tan et al., 2008). Given the heterogeneity of present diagnostic categories, alternate phenotyping strategies are needed to understand the genetic origins and mechanisms of psychiatric disorders and to facilitate the development of more valid psychiatric nosology and more effective interventions. This imperative spurred the National Institute of Mental Health (NIMH) to implement a Research Domain Criteria Project, or "RDoC" (see http://www.nimh.nih.gov/research-funding/rdoc/ index.shtml) strategy. The RDoC strategy involves developing, “...for research purposes, new ways of classifying mental disorders based on dimensions of observable behavior and neurobiological measures." RDoC encourages researchers to base their selection of subjects on dimensions that can be characterized along the causal chain from genes to molecules to circuits to behavior, rather than relying on DSM diagnoses (Figure 4 illustrates a theoretical causal chain for error processing). "Cognitive Systems" is one of the broad domains identified by RDoC for study, and below we argue that neuroimaging-based measures of cognition are more sensitive indices of genetic mechanisms than behavior.

While is well-accepted that genetic variation influences brain function and contributes to cognitive deficits in neuropsychiatric disorders, genetically mediated alterations in brain function are not always manifest at the level of behavior. Preserved behavior may reflect the use of an alternate strategy and/or the recruitment of compensatory neural circuitry. Conversely, disordered behavior may reflect not only the brain function of interest, but deficits of other systems, including of the motor output systems that are required to produce the behavior. Thus, behavior is an indirect and possibly unreliable index of genetic effects on brain function. Because brain function is a more direct index of genetic mechanisms than behavior, neuroimaging-based endophenotypes can result in increased effect sizes in studies of genetic variation. Gene effects on functional and structural neuroimaging phenotypes are often highly penetrant (e.g., Canli et al., 2005) and

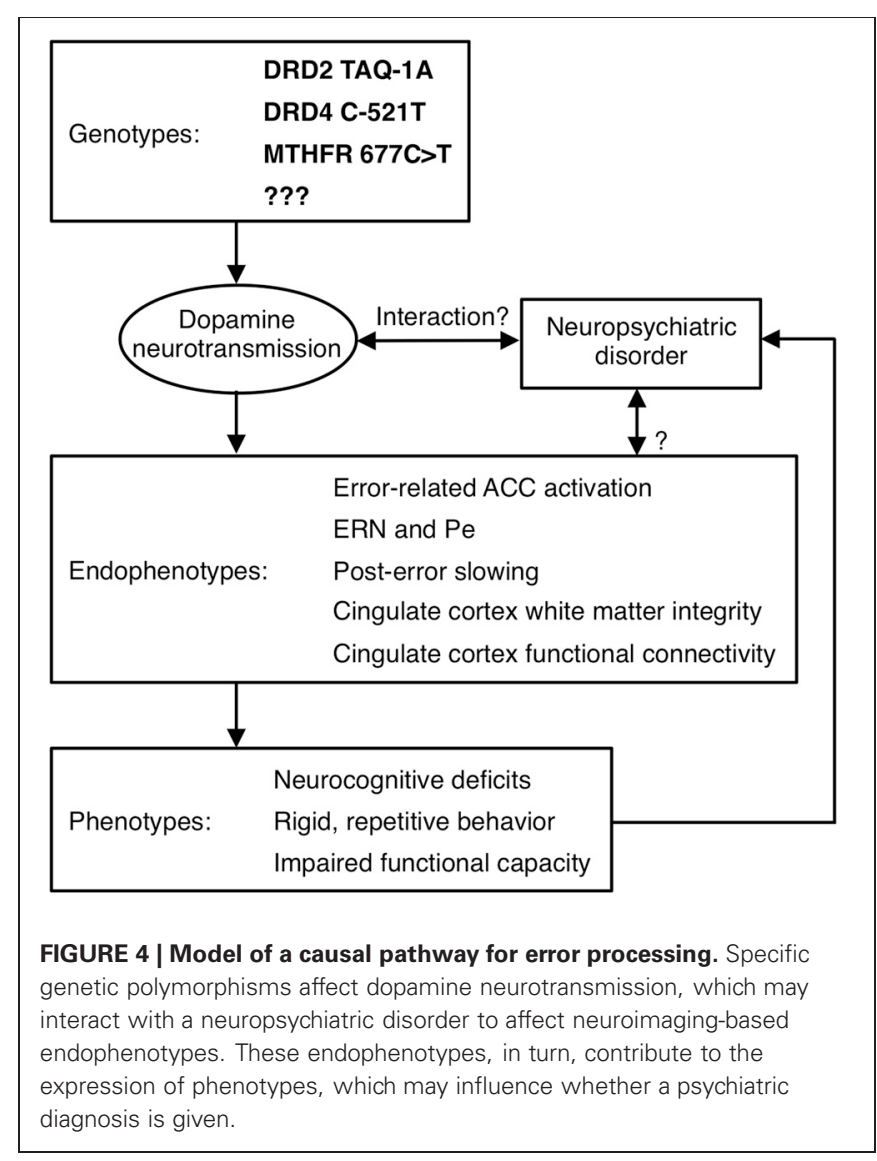




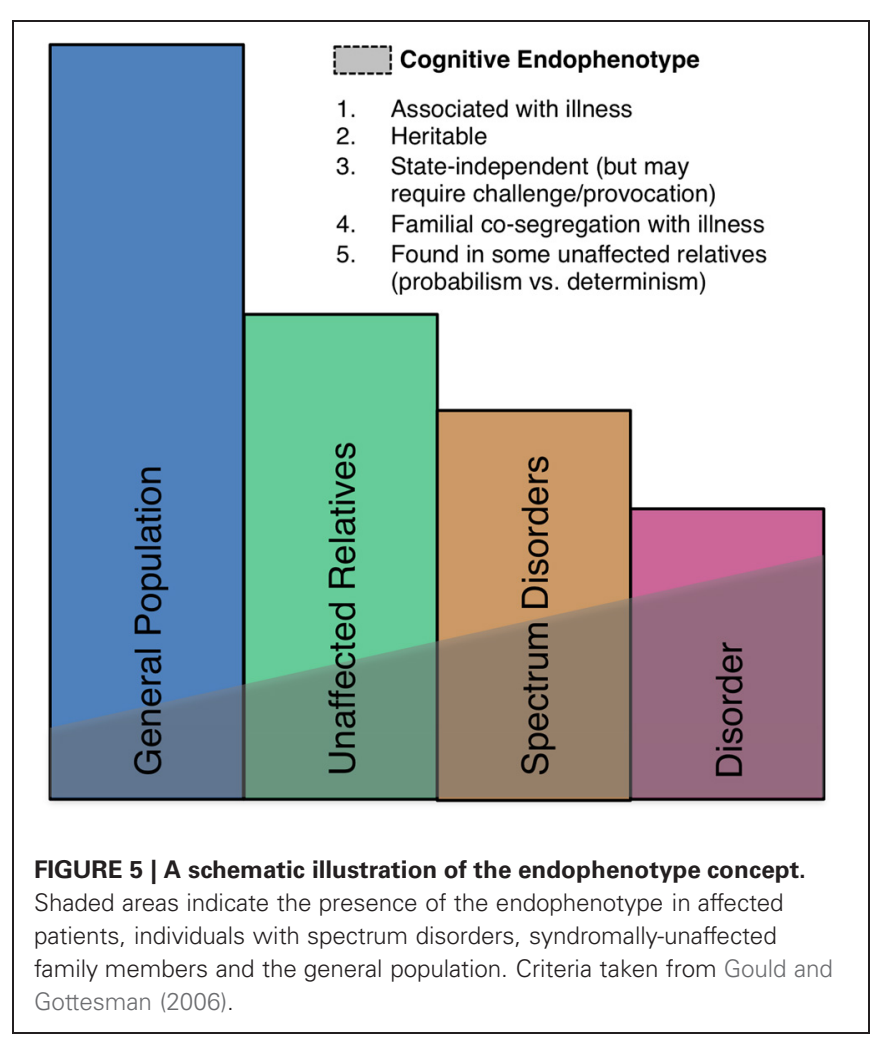

can be surprisingly large. This allows the investigation of substantially smaller sample sizes and makes it possible to detect significant genotype effects in the absence of overt behavioral differences (e.g., Roffman et al., 2008a). For these reasons, the study of genetic mediation using neuroimaging-based endophenotypes holds promise for uncovering susceptibility genes, mechanisms of illness, and targets for intervention (Hariri et al., 2006).

Neural markers of errors, such as the ERN, meet several important criteria as endophenotypes (Gottesman and Gould, 2003) including high heritability based on both sibling (Albrecht et al., 2008) and twin (Anokhin et al., 2008) studies, established neuroanatomical and neurochemical substrates, and association with psychiatric disorders, though they are also seen in the general population (Figure 5). There is also growing evidence of genetic mediation of neural error markers both in health and psychopathology.

\section{GENETIC VARIATION INFLUENCES ERROR PROCESSING IN HEALTH AND NEUROPSYCHIATRIC DISORDER (SEE TABLE 1 FOR A SUMMARY). \\ THE ROLE OF DOPAMINE IN ERROR PROCESSING}

Empirical work and theory document a critical role for the dopaminergic system, particularly D2-like DA receptors, in reinforcement learning (Schultz et al., 1997). Reinforcement learning theory has been extended to encompass error-based reinforcement learning and, as described above, both the ERN and error-related dACC activation are seen to arise from this DA dependent mechanism (Holroyd and Coles, 2002). Converging lines of evidence support a role for DA in error processing.
Table 1 | Genetic polymorphisms affecting EEG and fMRI error markers.

\begin{tabular}{ll}
\hline Polymorphism & Effect on error markers \\
\hline DRD2-TAQ-IA & Reduced dACC activation in A1 allele carriers \\
(rs1800497) & (Klein et al., 2007b), increased ERN in A1 \\
& carriers (Meyer et al., 2012), no effect on the \\
& ERN (Althaus et al., 2009). \\
\hline
\end{tabular}

\begin{tabular}{ll}
$\begin{array}{l}\text { DRD4 C-521T } \\
\text { (rs1800955) }\end{array}$ & $\begin{array}{l}\text { Increased ERN in T-allele carriers (Kramer et al., } \\
\text { 2007). }\end{array}$ \\
\hline DRD4 exon 3 VNTR & $\begin{array}{l}\text { Reduced ERN in 7R allele carriers (Biehl et al., } \\
\text { 2011). }\end{array}$ \\
\hline DAT1 3'-UTR VNTR & $\begin{array}{l}\text { Increased ERN (Meyer et al., 2012), increased } \\
\text { Pe (Althaus et al., 2010) and decreased Pe } \\
\text { (Biehl et al., 2011) in 9R allele carriers. }\end{array}$ \\
\hline $\begin{array}{l}\text { COMT Val }{ }^{158} \text { Met } \\
\text { (rs4680) }\end{array}$ & $\begin{array}{l}\text { In Val allele carriers increased ERN (Osinsky } \\
\text { et al., 2012) or a trend to an increased ERN } \\
\text { (Kramer et al., 2007), no effect on the ERN but } \\
\text { increased Pe in Met homozygotes (Frank et al., } \\
\text { 2007). }\end{array}$ \\
\hline
\end{tabular}

\begin{tabular}{ll}
\hline $\begin{array}{l}\text { MTHFR 677C }>\text { T } \\
\text { (rs1801133) }\end{array}$ & $\begin{array}{l}\text { Reduced dACC activation in T-allele carriers } \\
\text { (Roffman et al., 2011a,b). }\end{array}$ \\
\hline $\begin{array}{l}\text { Serotonin Transporter } \\
\text { 5-HTTLPR }\end{array}$ & $\begin{array}{l}\text { Increased ERN in short allele homozygotes } \\
\text { (Fallgatter et al., 2004), no effect on the ERN } \\
\text { (Olvet et al., 2010). }\end{array}$
\end{tabular}

5-HT1A Receptor Reduced ERN in G-allele carriers (Beste et al.,
C-1019G (rs6295) 2010).

BDNF Val ${ }^{66}$ Met (rs6265) Reduced ERN and post-error slowing in Met allele carriers (Beste et al., 2012).

\begin{tabular}{ll}
$\begin{array}{l}\text { NPSR Asn }{ }^{107} \| \mathrm{le} \\
\text { (rs324981) }\end{array}$ & $\begin{array}{l}\text { Increased ERN and post-error slowing in lle } \\
\text { carriers (Beste et al., 2013). }\end{array}$ \\
\hline
\end{tabular}

Individuals with Parkinson's Disease, which is caused by a loss of midbrain DA neurons, have a blunted ERN (Falkenstein et al., 2001; Ito and Kitagawa, 2006; Willemssen et al., 2009). Pharmacological manipulation of DA affects neural responses to errors. Haloperidol, a DA D2 receptor antagonist, blunted ERN amplitude in two studies (Zirnheld et al., 2004; De Bruijn et al., 2006), while D-amphetamine, an indirect DA agonist, increased it (De Bruijn et al., 2004). Additional support for a DA-dependent mechanism of error processing comes from findings that genetic polymorphisms affecting DA neurotransmission influence error markers in both health and neuropsychiatric disorders.

\section{DRD2 TAQ-IA}

The DA D2 receptor gene is a risk gene for schizophrenia (Shi et al., 2008) and the polymorphism, TAQ-1A (rs1800497), which is associated with schizophrenia (Parsons et al., 2007), predicts response to treatment with risperidone (Ikeda et al., 2008) and 
aripiprazole (Kwon et al., 2008). An fMRI study of healthy individuals (Klein et al., 2007b) found that A1 allele carriers, with putatively reduced striatal DA receptor density (Pohjalainen et al., 1998; Jonsson et al., 1999; Ritchie and Noble, 2003), showed decreased dACC activation in response to errors and decreased avoidance learning, suggesting that they were less efficient in learning from errors. A1 allele carriers also showed decreased functional connectivity of the dACC and striatum. With regard to the ERN, there are conflicting reports of no association with DRD2 TAQ-IA (Althaus et al., 2009) and an increased ERN amplitude in $A 1$ allele carriers (Meyer et al., 2012).

\section{DRD4 C-521T}

The DA D4 receptor gene $(D R D 4)$ is also a candidate gene for schizophrenia (Shi et al., 2008) and the -521 single nucleotide polymorphism (SNP) refers to a $C$-to- $T$ substitution in the DRD4 promoter region (rs1800955) with the $T$ allele resulting in $40 \%$ less transcriptional efficiency (Okuyama et al., 1999). The DRD4 -521C allele has been associated with schizophrenia (Okuyama et al., 1999; Xing et al., 2003; Allen et al., 2008) and healthy individuals homozygous for the $C$ allele showed a decreased ERN and decreased post-error slowing compared to $T$ homozygotes (Kramer et al., 2007).

\section{DRD4 EXON 3 VNTR}

Another $D R D 4$ polymorphism linked to error processing consists of a variable number of tandem repeats of a 48-base-pair sequence in the third exon (Van Tol et al., 1992). The most frequently occurring numbers of repeats are $4(4 R ; 70 \%), 7(7 R ; 20 \%)$, and $2(2 R$; $5 \%$ ) (Asghari et al., 1995). The $7 R$ allele has been associated with higher risk of OCD (Taj et al., 2013), with tics in OCD (Cruz et al., 1997), and with reduced ERN amplitude, but comparable Pe in healthy individuals (Biehl et al., 2011).

\section{THE DA TRANSPORTER (DAT1) 3'-UTR VNTR}

DAT1 plays a key role in regulating DA neurotransmission by facilitating re-uptake of DA in the synaptic cleft (Jaber et al., 1997). A polymorphism in the $3^{\prime}$-untranslated region ( $3^{\prime}$-UTR) of this gene consists of a variable number of tandem repeats of a 40-base-pair sequence, ranging from 3 to 11 copies of the repeated sequence, with the most common variants being 9 (9R;24\%) and $10(10 R ; 70 \%)$ repeats (Vandenbergh et al., 1992). Carriers of the $9 R$ allele have increased levels of DAT1 in the striatum (Van Dyck et al., 2005; Van De Giessen et al., 2009) and a trend for increased risk of OCD based on meta-analysis (Liu et al., 2012). The $9 R$ allele has also been associated with a larger ERN (referred to as $\triangle E R N$ in Meyer et al., 2012), and a larger Pe in one study (Althaus et al., 2010), but a smaller Pe in a second study (Biehl et al., 2011).

\section{COMT VAL ${ }^{158}$ MET}

A G-to-A SNP in the catechol-O-methyltransferase (COMT) gene leads to a valine-to-methionine substitution (COMTVal ${ }^{158}$ Met, rs4680). COMT metabolizes released DA and the Met allele significantly reduces COMT activity, leading to higher DA. The COMTVal ${ }^{158} \mathrm{Met}$ polymorphism has been studied extensively in relation to schizophrenia, and several meta-analysis have argued against association (Fan et al., 2005; Munafo et al., 2005; Okochi et al., 2009). While COMT Val ${ }^{158} \mathrm{Met}$ primarily affects DA availability in the prefrontal cortex (Egan et al., 2001; Craddock et al., 2006b), it may also have downstream effects on midbrain DA (Meyer-Lindenberg et al., 2005). Studies of error processing have yielded inconsistent findings, showing an increased amplitude of the ERN in Val allele carriers (Osinsky et al., 2012), only a trend-level enhancement of the ERN in Val compared to Met homozygotes (Kramer et al., 2007), and no effect of COMT $\mathrm{Val}^{158} \mathrm{Met}$ on the ERN but an increased Pe in Met homozygotes compared to Val carriers (Frank et al., 2007).

\section{MTHFR $677 C>T$}

The hypofunctional $677 T$ variant in the methylenetetrahydrofolate reductase gene (MTHFR $677 C>T, r s 1801133$ ) has been associated with increased risk for schizophrenia (Gilbody et al., 2007; Allen et al., 2008), executive dysfunction in schizophrenia (Roffman et al., 2008b), and negative symptoms (Roffman et al., 2008c). Several steps in the DA lifecycle rely on methylation reactions regulated by MTHFR (Friso et al., 2002) and each copy of the $T$ allele reduces MTHFR activity by 35\% (Frosst et al., 1995). The $T$ allele has been shown to reduce dorsolateral prefrontal cortex fMRI activation during working memory performance in schizophrenia, both on its own, and via epistatic interactions with the low-DA COMT158Val allele, supporting a role of MTHFR in prefrontal DA signaling (Roffman et al., 2008a). There is also indirect evidence linking MTHFR to striatal DA. MTHFR is a key enzyme in the metabolism of homocysteine, which has toxic effects on DA neurons in the striatum of rats (Imamura et al., 2007). In alcohol dependent individuals, MTHFR 677T has been associated with higher plasma levels of homocysteine and increased risk of withdrawal seizures, which were interpreted to reflect the neurotoxic effects of homocysteine on the mesencephalic DA system (Lutz et al., 2006, 2007; Lutz, 2008).

In a prior study of executive function in schizophrenia (Roffman et al., 2008b), MTHFR 677T was specifically related to a behavioral index of error processing, namely increased perseverative errors on the Wisconsin Card Sort Test, which reflect a failure to use feedback to adjust behavior. Recent work has demonstrated significant $677 T$ allele-related reductions in error related fMRI activation of the dACC in healthy individuals and in two independent samples of patients with schizophrenia (Roffman et al., 2011a,b). The reductions in dACC activation were linearly related to allele dose regardless of diagnosis (Roffman et al., 2011b). This suggests that MTHFR 677T mediates error processing in both health and schizophrenia.

\section{OTHER GENETIC VARIATION RELATED TO ERROR PROCESSING The serotonin transporter gene (5-HTTLR)}

Evidence linking serotonin to ACC function and structure comes from studies of a functional length variation in the transcriptional control region of the serotonin transporter gene in healthy individuals. This polymorphism was associated with differences in the anatomy and function of the amygdala- rACC circuit in healthy individuals (Pezawas et al., 2005), which has been implicated in generating and learning from negative affect (for review 
see Drevets, 2000; Baxter and Murray, 2002; Zald, 2003). This learning may extend to errors since both the rACC and amygdala respond to errors, and together, activation in these structures predicts error rate (Polli et al., 2008, 2009).

More direct evidence of a role for this polymorphism in error processing are findings of a significantly increased ERN amplitude and a trend to increased Pe amplitude in short allele homozygotes, who presumably produce less serotonin transporter transcript, compared to long allele homozygotes (Fallgatter et al., 2004). A larger study, however, failed to replicate the association of 5-HTTLPR genotype with ERN amplitude (Olvet et al., 2010).

\section{5-HT1A receptor gene C-1019G}

A SNP present in about a third of the population consisting of an extra base pair in the promoter region of the 5 -HT1A receptor gene $(C-1019 G$, rs6295) has been associated with reduced ERN and post-error slowing (Beste et al., 2010). The presence of a guanine nucleotide prevents binding of repressor proteins, which leads to enhanced gene expression and reduced serotonergic transmission (Lemonde et al., 2003). The $G$ allele has been linked to increased risk of schizophrenia (Huang et al., 2004) and to worse treatment outcomes (Reynolds et al., 2006; Mossner et al., 2009), but a meta-analysis reported no association with schizophrenia (Kishi et al., 2011).

\section{BDNF Val ${ }^{66}$ Met}

The brain-derived neurotrophic factor (BDNF) is a nerve growth factor thought to facilitate synaptic connections in the brain (Cohen-Cory et al., 1996). A SNP in the eponymous gene, which encodes for BDNF, results in valine-to-methionine substitution in the prodomain of the protein (BDNF $\mathrm{Val}^{66} \mathrm{Met}$, rs6265) that leads to reduced activity-dependent secretion of BDNF (Egan et al., 2003). One meta-analysis found an elevated risk for schizophrenia in homozygous Met carriers (Gratacos et al., 2007), but another did not (Kanazawa et al., 2007). The Met allele has been associated with earlier onset of schizophrenia (Chao et al., 2008) and reductions of ERN amplitude and post-error slowing in healthy individuals (Beste et al., 2012).

\section{NPSR Asn ${ }^{107}$ IIe}

Neuropeptide S (NPS) is a 20 amino-acid peptide that modulates stress and arousal (Okamura and Reinscheid, 2007). An A-to-T substitution at position 107 of the gene encoding for the NPS receptor (NPSR) leads to an amino acid exchange from Asn to Ile (Asn ${ }^{107}$ Ile, rs324981) and increases the efficacy of NPS about tenfold (Reinscheid et al., 2005). The T allele is thought to be related to anxiety disorders, particularly panic disorder (Domschke et al., 2011), and is associated with an increased ERN and more pronounced post-error slowing in healthy individuals (Beste et al., 2013).

\section{CHALLENGES TO THE STUDY OF NEURAL INDICES ERROR PROCESSING AS ENDOPHENOTYPES FAILURES OF REPLICATION IN IMAGING-GENETICS STUDIES}

Failures of replication are extremely common in imaging-genetics studies and represent a major challenge. Imaging-genetics findings are often based on relatively small samples and negative results are much less likely to be published. Smaller samples are often justified based on evidence that neuroimaging-based endophenotypes result in increased effect sizes in studies of genetic variation than behavior or diagnosis. The pragmatic justification is that neuroimaging studies are costly and require considerable infrastructure to accomplish. Relatively small and comprehensive studies can identify the most promising cognitive constructs and endophenotypes, which can then be exported for use in larger multisite studies of patients, relatives, and racially and ethnically homogeneous groups as has been done for studies of other putative cognitive endophenotypes (e.g., Turetsky et al., 2008; Radant et al., 2010). Studies in developing countries can complement and extend these efforts by identifying overlapping and distinct genetic contributions in non-western populations (e.g., Chan et al., 2010). To protect against false positive associations in smaller studies, it is often advisable to investigate the effects of only a limited set of polymorphisms that are selected based on stringent criteria and to seek convergence in the data. This strategy can maximize scientific yield while minimizing the risk of spurious findings by focusing on a hypothesis-driven set of loci that affect specific neural mechanisms, and are most likely to affect a particular endophenotype or set of related endophenotypes given the current state of knowledge. A limitation to this approach is that it will not represent the full complement of genes that influence the phenotypes of interest.

\section{METHODOLOGICAL DIFFERENCES ACROSS STUDIES MAY LEAD TO CONFLICTING FINDINGS}

Another challenge in the error processing literature is that the definition and measurement of neural indices of error processing vary across studies. The ERN, for example, can be defined based on the peak of negativity in either the error waveform alone or in the difference (error vs. correct) waveform. It is arguable which method is more valid. Such measurement differences can affect study outcomes as can be illustrated in OCD, which is often characterized by exaggerated neural responses on both correct and error trials. Several studies reporting an increased ERN in OCD, or in non-clinical populations with OCD symptoms, defined it using only the error trial (Gehring et al., 2000; Johannes et al., 2001; Hajcak and Simons, 2002; Endrass et al., 2008, 2010). In at least two of these studies, the waveform for correct trials was also more negative in OCD participants than controls (referred to as the correct-related negativity or CRN). Consequently, had the ERN been defined as the difference waveform, it might not have been greater in OCD patients than controls.

Methodological differences may also contribute to discrepancies in fMRI results. For example, most standard fMRI analysis techniques assume a shape to the hemodynamic response. While this is a statistically powerful technique when the models are correct, a single assumed model is unlikely to be valid across all brain regions and stimulus types (Duann et al., 2002) and, importantly, model inaccuracies may lead to the misattribution of activity to adjacent events (Manoach et al., 2003). Thus, it is possible that in some studies, increased ACC activation on error trials may reflect greater activation while planning or preparing the response rather than an exaggerated response to the error. Finite Impulse Response (FIR, Burock and Dale, 2000; Jansma et al., 2013) or 
other models that make no a priori assumptions about the shape of the hemodynamic response, may more accurately distinguish preparatory activation from error-related activation, and can also be used to evaluate the temporal characteristics of the hemodynamic response, which may differ between study groups (e.g., Dyckman et al., 2011).

Conflicting findings of error processing deficits in particular disorders may also arise from a number of other factors such as the use of different tasks and levels of difficulty, the characteristics of the samples studied such as whether certain symptoms are present, treatment with medications, and task performance (e.g., Mathews et al., 2012). By affecting neurotransmitter systems that mediate error responses, medications such as antipsychotics, selective serotonin reuptake inhibitors, and antidepressants may affect outcome measures and obscure group differences and effects of genetic variation. Task performance is also important to consider in evaluating error indices. More frequent errors are also more predictable, and ERN amplitude is thought to code the degree to which errors are unexpected (Holroyd and Coles, 2002; Brown and Braver, 2005), consistent with findings of inverse correlations between error rate and ERN amplitude (Gehring et al., 1993; Hajcak et al., 2003; Agam et al., 2011). The same may be true for dACC activation, which also correlates with error rate in some studies (e.g., Polli et al., 2008). Thus, different error rates in patient and control samples or in pre- and post-treatment conditions (e.g., Sokhadze et al., 2012a) represents a potential confound that could be statistically controlled (e.g., Polli et al., 2008). For example, in several ERN studies ASD participants had a higher error rate than controls (e.g., Sokhadze et al., 2010, 2012b; South et al., 2010), making it unclear whether the blunted ERN reflected more frequent errors or deficient error recognition and signaling.

\section{LIMITATIONS TO THE CLINICAL UTILITY OF ERROR PROCESSING ENDOPHENOTYPES}

Unlike neurodegenerative disorders such as Alzheimer's Disease, which are associated with specific neuropathologies, neuropsychiatric disorders likely have multiple overlapping etiologies and neuropathologies. Consequently, neuropsychiatric disorders lack sensitive and specific pathophysiological markers such as amyloid beta protein, which is specific to Alzheimer's Disease, is thought to cause the associated dementia, and can be measured in vivo to assess the risk of developing symptoms and response to therapy (Klunk, 2011). Error processing endophenotypes, in contrast to amyloid beta protein, do not index a known, specific neuropathology and their diagnostic specificity remains to be established. Also, unlike amyloid beta protein, whose presence is usually associated with pathology, neural error markers are normally present and abnormality is defined as statistical deviation of their parameters from the norm, which varies from study to study. Measurement variability, the lack of consensus definitions of error markers, and the absence of large-scale studies make it difficult to define clear cut-offs for "normality." In addition, error processing endophenotypes, such as a blunted or exaggerated ERN or error-related dACC activation, are only probabilistically associated with illness, they do not determine illness. The cognitive dysfunction that they index may make illness more probable, but is likely just one of a number of cumulative hits of relatively small effect. Given that we lack a comprehensive understanding of the genetic contributions to these markers, it is difficult to distinguish "false positives" (i.e., abnormal error markers in the absence of genetic risk in an otherwise healthy individual) from valid genetic vulnerability for a disorder that has not manifested itself for environmental reasons or due to other, protective, epigenetic or genetic factors. Similarly, because endophenotypes are only probabilistically related to illness and current diagnostic categories are heterogeneous, they may only be present in a subset of individuals within a given diagnostic group.

\section{ESTABLISHING THE CLINICAL RELEVANCE OF ERROR PROCESSING DEFICITS}

While there is clear evidence that deficient error processing is associated with symptoms and functional outcome in neuropsychiatric disorders, further research is required to fully elaborate the bases of these relations both within and across disorders. If, as we and others have proposed, deficient error processing mediates the pathway between genetic predisposition and illness by interfering with adaptive responses to outcomes (e.g., Olvet and Hajcak, 2008), early intervention and prevention may be possible, for example, in individuals at high risk for schizophrenia who show a blunted ERN (e.g., Laurens et al., 2010; Perez et al., 2012; Simmonite et al., 2012). It may also be possible to intervene to prevent relapse. Two recent studies demonstrate that error-related dACC activation predicts relapse and time to relapse in cocaine-dependent individuals (Luo et al., 2013) and recidivism in criminal offenders (Aharoni et al., 2013). These findings provide a rationale for the development of interventions to ameliorate error processing deficits in neuropsychiatric disorders as well as other populations characterized by repetitive, maladaptive behaviors.

\section{CONCLUSIONS}

The existing literature on error processing allows the generation of biologically plausible hypotheses concerning the effects of genetic variation on well-validated and heritable indices of error processing that are abnormal in neuropsychiatric disorders, show evidence of diagnostic specificity, contribute to disability, and are thought to be mediated by specific neural mechanisms. Understanding the genetic mediation and mechanisms of error processing deficits in neuropsychiatric disorders may eventually lead to the development of specifically targeted interventions and enable the use genetic information to identify individuals most likely to benefit from these treatments. This can substantially reduce outcome variability, thereby increasing power, and reducing the required sample size and cost of treatment trials. The findings of imaging-genetics investigations may also provide novel neural and behavioral targets for treatment and sensitive surrogate markers of treatment response. Treating error processing deficits may significantly affect functional outcome in neuropsychiatric disorders or possibly even prevent onset or relapse since error signals provide crucial information for flexible adaptation to changing environments, and deficits in learning from errors, as indexed by abnormal neural responses and reduced 
behavioral adaptation, likely substantially contribute to rigid, perseverative, and maladaptive patterns of behavior. Given the dearth of effective interventions for cognitive deficits in neuropsychiatric disorders, this represents a promising approach.

\section{REFERENCES}

Agam, Y., Carey, C., Barton, J. J. S., Dyckman, K. A., Lee, A. K. C., Vangel, M., et al. (2013). Network dynamics underlying speedaccuracy trade-offs in response to errors. PLOS ONE (in press).

Agam, Y., Hamalainen, M. S., Lee, A. K., Dyckman, K. A., Friedman, J. S., Isom, M., et al. (2011). Multimodal neuroimaging dissociates hemodynamic and electrophysiological correlates of error processing. Proc. Natl. Acad. Sci. U.S.A. 108, 17556-17561. doi: 10.1073/pnas.1103475108

Agartz, I., Andersson, J. L., and Skare, S. (2001). Abnormal brain white matter in schizophrenia: a diffusion tensor imaging study. Neuroreport 12, 2251-2254. doi: 10.1097/00001756200107200-00041

Aharoni, E., Vincent, G. M., Harenski, C. L., Calhoun, V. D., SinnottArmstrong, W., Gazzaniga, M. S., et al. (2013). Neuroprediction of future rearrest. Proc. Natl. Acad. Sci. U.S.A. 110, 6223-6228. doi: $10.1073 /$ pnas. 1219302110

Alain, C., McNeely, H. E., He, Y., Christensen, B. K., and West, R. (2002). Neurophysiological evidence of error-monitoring deficits in patients with schizophrenia. Cereb. Cortex 12, 840-846. doi: 10.1093/cercor/12.8.840

Albrecht, B., Brandeis, D., Uebel, H., Heinrich, H., Mueller, U. C., Hasselhorn, M., et al. (2008). Action monitoring in boys with attentiondeficit/hyperactivity disorder, their nonaffected siblings, and normal control subjects: evidence for an endophenotype. Biol. Psychiatry 64, 615-625. doi: 10.1016/j.biopsych.2007.12.016

Allen, N. C., Bagade, S., McQueen, M. B., Ioannidis, J. P., Kavvoura, F. K., Khoury, M. J., et al. (2008). Systematic meta-analyses and field synopsis of genetic association studies in schizophrenia: the SzGene database. Nat. Genet. 40, 827-834. doi: 10.1038/ng.171

Althaus, M., Groen, Y., Wijers, A. A., Minderaa, R. B., Kema, I. P., Dijck, J. D., et al. (2010). Variants of the SLC6A3 (DAT1) polymorphism affect performance monitoring-related cortical evoked potentials that are associated with
ADHD. Biol. Psychol. 85, 19-32. doi: 10.1016/j.biopsycho.2010.04.007

Althaus, M., Groen, Y., Wijers, A. A., Mulder, L. J., Minderaa, R. B., Kema, I. P., et al. (2009). Differential effects of 5-HTTLPR and DRD2/ANKK1 polymorphisms on electrocortical measures of error and feedback processing in children. Clin. Neurophysiol. 120, 93-107. doi: 10.1016/j.clinph.2008.10.012

Andalman, A. S., and Fee, M. S. (2009). A basal ganglia-forebrain circuit in the songbird biases motor output to avoid vocal errors. Proc. Natl. Acad. Sci. U.S.A. 106, 12518-12523. doi: 10.1073/pnas. 0903214106

Anokhin, A. P., Golosheykin, S., and Heath, A. C. (2008). Heritability of frontal brain function related to action monitoring. Psychophysiology 45, 524-534. doi: 10.1111/j.14698986.2008.00664.x

Ardekani, B. A., Nierenberg, J., Hoptman, M. J., Javitt, D. C., and Lim, K. O. (2003). MRI study of white matter diffusion anisotropy in schizophrenia. Neuroreport 14, 2025-2029. doi: 10.1097/00001756200311140-00004

Asghari, V., Sanyal, S., Buchwaldt, S., Paterson, A., Jovanovic, V., and Van Tol, H. H. (1995). Modulation of intracellular cyclic AMP levels by different human dopamine D4 receptor variants. J. Neurochem. 65, 1157-1165. doi: 10.1046/j.14714159.1995.65031157.x

Barnea-Goraly, N., Kwon, H., Menon, V., Eliez, S., Lotspeich, L., and Reiss, A. L. (2004). White matter structure in autism: preliminary evidence from diffusion tensor imaging. Biol. Psychiatry 55, 323-326. doi: 10.1016/j.biopsych. 2003.10.022

Bates, A. T., Kiehl, K. A., Laurens, K. R., and Liddle, P. F. (2002). Error-related negativity and correct response negativity in schizophrenia. Clin. Neurophysiol. 113, 1454-1463. doi: 10.1016/S13882457(02)00154-2

Baxter, M. G., and Murray, E. A. (2002). The amygdala and reward. Nat. Rev. Neurosci. 3, 563-573. doi: $10.1038 / \mathrm{nrn} 875$

Benes, F. M. (1993). Neurobiological investigations in cingulate cortex of schizophrenic brain.

\section{ACKNOWLEDGMENTS}

The authors are grateful to Jordan Smoller and Daniel Z. Press for consultation. Support: National Institute for Mental Health: R01 MH67720 (Dara S. Manoach); F32 MH088081 (Yigal Agam).

Schizophr. Bull. 19, 537-549. doi: 10.1093/schbul/19.3.537

Benes, F. M. (2000). Emerging principles of altered neural circuitry in schizophrenia. Brain Res. Brain Res. Rev. 31, 251-269. doi: 10.1016/S0165-0173(99)00041-7

Beste, C., Domschke, K., Kolev, V., Yordanova, J., Baffa, A., Falkenstein, M., et al. (2010). Functional 5-HT1a receptor polymorphism selectively modulates error-specific subprocesses of performance monitoring. Hum. Brain Mapp. 31, 621-630.

Beste, C., Kolev, V., Yordanova, J., Domschke, K., Falkenstein, M., Baune, B. T., et al. (2012). The role of the BDNF Val66Met polymorphism for the synchronization of error-specific neural networks. J. Neurosci. 30, 10727-10733. doi: 10.1523/JNEUROSCI.2493-10.2010

Beste, C., Konrad, C., Uhlmann, C., Arolt, V., Zwanzger, P., and Domschke, K. (2013). Neuropeptide S receptor (NPSR1) gene variation modulates response inhibition and error monitoring. Neuroimage 71, 1-9. doi: 10.1016/j.neuroimage.2013.01.004

Biehl, S. C., Dresler, T., Reif, A., Scheuerpflug, P., Deckert, J., and Herrmann, M. J. (2011). Dopamine transporter (DAT1) and dopamine receptor D4 (DRD4) genotypes differentially impact on electrophysiological correlates of error processing. PLoS ONE 6:e28396. doi: 10.1371/journal.pone.0028396

Bishop, S. L., Richler, J., Cain, A. C., and Lord, C. (2007). Predictors of perceived negative impact in mothers of children with autism spectrum disorder. Am. J. Ment. Retard. 112, 450-461. doi: 10.1352/0895-8017 (2007)112[450:POPNII]2.0.CO;2

Bogte, H., Flamma, B., Van Der Meere, J., and Van Engeland, H. (2007). Post-error adaptation in adults with high functioning autism. Neuropsychologia 45, 1707-1714. doi: $\quad 10.1016 /$ j.neuropsychologia. 2006.12.020

Brazdil, M., Roman, R., Falkenstein, M., Daniel, P., Jurak, P., and Rektor, I. (2002). Error processing-evidence from intracerebral ERP recordings. Exp. Brain Res. 146, 460-466. doi: 10.1007/s00221-002-1201-y

Breiter, H. C., Rauch, S. L., Kwong, K. K., Baker, J. R., Weisskoff, R.
M., Kennedy, D. N., et al. (1996) Functional magnetic resonance imaging of symptom provocation in obsessive-compulsive disorder. Arch. Gen. Psychiatry 53, 595-606. doi: 10.1001/archpsyc.1996.01830070041008

Brown, J. W., and Braver, T. S. (2005). Learned predictions of error likelihood in the anterior cingulate cortex. Science 307, 1118-1121. doi: 10.1126/science. 1105783

Broyd, S. J., Demanuele, C., Debener, S., Helps, S. K., James, C. J., and Sonuga-Barke, E. J. (2009). Default-mode brain dysfunction in mental disorders: a systematic review. Neurosci. Biobehav. Rev. 33, 279-296. doi: 10.1016/j.neubiorev.2008.09.002

Buchsbaum, M. S., Tang, C. Y., Peled, S., Gudbjartsson, H., Lu, D., Hazlett, E. A., et al. (1998). MRI white matter diffusion anisotropy and PET metabolic rate in schizophrenia. Neuroreport 9, 425-430. doi: 10.1097/00001756199802160-00013

Buckner, R. L., Andrews-Hanna, J. R., and Schacter, D. L. (2008). The brain's default network: anatomy, function, and relevance to disease. Ann. N.Y. Acad. Sci. 1124, 1-38. doi: 10.1196/annals.1440.011

Burns, J., Job, D., Bastin, M. E. Whalley, H., Macgillivray, T. Johnstone, E. C., et al. (2003). Structural disconnectivity in schizophrenia: a diffusion tensor magnetic resonance imaging study. Br. J. Psychiatry 182, 439-443. doi: 10.1192/bjp.182.5.439

Burock, M. A., and Dale, A. M. (2000). Estimation and detection of eventrelated fMRI signals with temporally correlated noise: a statistically efficient and unbiased approach. Hum. Brain Mapp. 11, 249-260.

Bush, G., Luu, P., and Posner, M. I. (2000). Cognitive and emotional influences in anterior cingulate cortex. Trends Cogn. Sci. 4, 215-222. doi: 10.1016/S1364-6613 (00)01483-2

Bush, G., Whalen, P. J., Rosen, B. R. Jenike, M. A., McInerney, S. C., and Rauch, S. L. (1998). The counting stroop: an interference task specialized for functional neuroimagingvalidation study with functional MRI. Hum. Brain Mapp. 6, 270-282. 
Canli, T., Omura, K., Haas, B. W., Fallgatter, A., Constable, R. T., and Lesch, K. P. (2005). Beyond affect: a role for genetic variation of the serotonin transporter in neural activation during a cognitive attention task. Proc. Natl. Acad. Sci. U.S.A. 102, 12224-12229. doi: 10.1073/pnas.0503880102

Carrasco, M., Harbin, S. M., Nienhuis, J. K., Fitzgerald, K. D., Gehring, W. J., and Hanna, G. L. (2013). Increased error-related brain activity in youth with obsessivecompulsive disorder and unaffected siblings. Depress. Anxiety 30, 39-46. doi: $10.1002 /$ da. 22035

Carter, C. S., Macdonald, A. W. 3rd., Ross, L. L., and Stenger, V. A. (2001). Anterior cingulate cortex activity and impaired selfmonitoring of performance in patients with schizophrenia: an event-related fMRI study. Am. J. Psychiatry 158, 1423-1428. doi: $\quad$ 10.1176/appi.ajp.158.9. 1423

Chan, R. C., Gottesman, Ii., Ge, X., and Sham, P. C. (2010). Strategies for the study of neuropsychiatric disorders using endophenotypes in developing countries: a potential databank from china. Front. Hum. Neurosci. 4:207. doi: 10.3389/fnhum.2010.00207

Chao, H. M., Kao, H. T., and Porton, B. (2008). BDNF Val66Met variant and age of onset in schizophrenia. Am. J. Med. Genet. B Neuropsychiat. Genet. 147B, 505-506. doi: 10.1002/ajmg.b.30619

Cheng, Y., Chou, K. H., Chen, I. Y., Fan, Y. T., Decety, J., and Lin, C. P. (2010). Atypical development of white matter microstructure in adolescents with autism spectrum disorders. Neuroimage 50, 873-882. doi: 10.1016/j.neuroimage.2010.01.011

Cohen-Cory, S., Escandon, E., and Fraser, S. E. (1996). The cellular patterns of BDNF and trkB expression suggest multiple roles for BDNF during Xenopus visual system development. Dev. Biol. 179, 102-115. doi: 10.1006/dbio.1996.0244

Craddock, N., O'Donovan, M. C., and Owen, M. J. (2006a). Genes for schizophrenia and bipolar disorder? Implications for psychiatric nosology. Schizophr. Bull. 32, 9-16. doi: 10.1093/schbul/sbj033

Craddock, N., Owen, M. J., and O'Donovan, M. C. (2006b). The catechol-O-methyl transferase (COMT) gene as a candidate for psychiatric phenotypes: evidence and lessons. Mol.
Psychiatry 11, 446-458. doi: 10.1038/sj.mp.4001808

Crespi, B., Stead, P., and Elliot, M. (2010). Evolution in health and medicine sackler colloquium: comparative genomics of autism and schizophrenia. Proc. Natl. Acad. Sci. U.S.A. 107(Suppl. 1), 1736-1741. doi: 10.1073/pnas.0906080106

Cross-Disorder Group of the Psychiatric Genomics, C., Smoller, J. W., Craddock, N., Kendler, K., Lee, P. H., Neale, B. M., et al. (2013). Identification of risk loci with shared effects on five major psychiatric disorders: a genome-wide analysis. Lancet 381, 1371-1379. doi: 10.1016/S0140-6736(12)62129-1

Cruz, C., Camarena, B., King, N., Paez, F., Sidenberg, D., De La Fuente, J. R., et al. (1997). Increased prevalence of the seven-repeat variant of the dopamine D4 receptor gene in patients with obsessive-compulsive disorder with tics. Neurosci. Lett. 231, 1-4. doi: 10.1016/S0304-3940(97)00523-5

De Bruijn, E. R., Hulstijn, W., Verkes, R. J., Ruigt, G. S., and Sabbe, B. G. (2004). Drug-induced stimulation and suppression of action monitoring in healthy volunteers. Psychopharmacology (Berl.) 177, 151-160. doi: 10.1007/s00213-004-1915-6

De Bruijn, E. R., Sabbe, B. G., Hulstijn, W., Ruigt, G. S., and Verkes, R. J. (2006). Effects of antipsychotic and antidepressant drugs on action monitoring in healthy volunteers. Brain Res. 1105, 122-129. doi: 10.1016/j.brainres.2006.01.006

Debener, S., Ullsperger, M., Siegel, M., Fiehler, K., Von Cramon, D. Y., and Engel, A. K. (2005). Trial-by-trial coupling of concurrent electroencephalogram and functional magnetic resonance imaging identifies the dynamics of performance monitoring. J. Neurosci. 25, 11730-11737. doi: 10.1523/JNEUROSCI.3286-05.2005

Dehaene, S., Posner, M. I., and Tucker, D. M. (1994). Localization of a neural system for error detection and compensation. Psychol. Sci. 5, 303-305. doi: 10.1111/j.14679280.1994.tb00630.x

Devinsky, O., Morrell, M. J., and Vogt, B. A. (1995). Contributions of anterior cingulate cortex to behaviour. Brain 118(Pt 1), 279-306. doi: 10.1093/brain/118.1.279

Domschke, K., Reif, A., Weber, H., Richter, J., Hohoff, C., Ohrmann, P., et al. (2011). Neuropeptide S receptor gene - converging evidence for a role in panic disorder.
Mol. Psychiatry 16, 938-948. doi: 10.1038/mp.2010.81

Donamayor, N., Marco-Pallares, J., Heldmann, M., Schoenfeld, M. A., and Munte, T. F. (2011) Temporal dynamics of reward processing revealed by magnetoencephalography. Hum. Brain Mapp. 32, 2228-2240. doi: 10.1002/hbm.21184

Dougherty, D. D., Baer, L., Cosgrove, G. R., Cassem, E. H., Price, B. H., Nierenberg, A. A., et al. (2002). Prospective long-term follow-up of 44 patients who received cingulotomy for treatment-refractory obsessive-compulsive disorder. Am. J. Psychiatry 159, 269-275. doi: 10.1176/appi.ajp.159.2.269

Drevets, W. C. (2000). Neuroimaging studies of mood disorders. Biol. Psychiatry 48, 813-829. doi: 10.1016/S0006-3223(00)01020-9

Drevets, W. C., and Raichle, M. E. (1998). Reciprocal suppression of regional cerebral blood flow during emotional versus higher cognitive processes: implications for interactions between emotion and cognition. Cognit. Emot. 12, 353-385. doi: 10.1080/026999398379646

Duann, J. R., Jung, T. P., Kuo, W. J., Yeh, T. C., Makeig, S., Hsieh, J. C., et al. (2002). Single-trial variability in event-related BOLD signals. Neuroimage 15, 823-835. doi: 10.1006/nimg.2001.1049

Dyckman, K. A., Lee, A. K. C., Agam, Y., Vangel, M., Goff, D. C., Barton, J. J. S., et al. (2011). Abnormally persistent fMRI activation during antisaccades in schizophrenia: a neural correlate of perseveration? Schizophr. Res. 132, 62-68. doi: 10.1016/j.schres.2011. 07.026

Egan, M. F., Goldberg, T. E., Kolachana, B. S., Callicott, J. H., Mazzanti, C. M., Straub, R. E., et al. (2001). Effect of COMT Val108/158 Met genotype on frontal lobe function and risk for schizophrenia. Proc. Natl. Acad. Sci. U.S.A. 98, 6917-6922. doi 10.1073/pnas.111134598

Egan, M. F., Kojima, M., Callicott, J. H., Goldberg, T. E., Kolachana, B. S., Bertolino, A., et al. (2003) The BDNF val66met polymorphism affects activity-dependent secretion of BDNF and human memory and hippocampal function. Cell 112, 257-269. doi: $\quad 10.1016 / 50092-8674(03)$ 00035-7

Eichele, T., Debener, S., Calhoun, V. D., Specht, K., Engel, A. K., Hugdahl, K., et al. (2008). Prediction of human errors by maladaptive changes in event-related brain networks. Proc. Natl. Acad. Sci. U.S.A. $105, \quad 6173-6178 . \quad$ doi: 10.1073/pnas.0708965105

Endrass, T., Franke, C., and Kathmann, N. (2005). Error awareness in a saccade countermanding task. J. Psychophysiol. 19, 275-280. doi: 10.1027/0269-8803.19.4.275

Endrass, T., Klawohn, J., Schuster, F., and Kathmann, N. (2008). Overactive performance monitoring in obsessive-compulsive disorder: ERP evidence from correct and erroneous reactions. Neuropsychologia 46, 1877-1887. doi: $\quad 10.1016 /$ j.neuropsychologia. 2007.12.001

Endrass, T., Reuter, B., and Kathmann, N. (2007). ERP correlates of conscious error recognition: aware and unaware errors in an antisaccade task. Eur. J. Neurosci. 26, 1714-1720. doi: 10.1111/j.1460-9568.2007.05785.x

Endrass, T., Schuermann, B., Kaufmann, C., Spielberg, R., Kniesche, R., and Kathmann, N. (2010). Performance monitoring and error significance in patients with obsessive-compulsive disorder. Biol. Psychol. 84, 257-263. doi: 10.1016/j.biopsycho.2010.02.002

Eriksen, B. A., and Eriksen, C. W. (1974). Effects of noise letters upon the identification of a target letter in a nonsearch task. Percept. Psychophys 16, 143-149. doi: 10.3758/BF03203267

Falkenstein, M., Hielscher, H., Dziobek, I., Schwarzenau, P., Hoormann, J., Sunderman, B., et al. (2001) Action monitoring, error detection, and the basal ganglia: an ERP study. Neuroreport 12, 157-161. doi: 10.1097/00001756-20010122000039

Falkenstein, M., Hohnsbein, J., Hoormann, J., and Blanke, L. (1991). Effects of crossmodal divided attention on late ERP components. II. Error processing in choice reaction tasks. Electroencephalogr. Clin. Neurophysiol. 78, 447-455. doi: 10.1016/0013-4694(91)90062-9

Fallgatter, A. J., Herrmann, M. J., Roemmler, J., Ehlis, A. C., Wagener, A., Heidrich, A., et al. (2004). Allelic variation of serotonin transporter function modulates the brain electrical response for error processing. Neuropsychopharmacology 29, 1506-1511. doi: 10.1038/ sj.npp.1300409

Fan, J. B., Zhang, C. S., Gu, N. F., Li, X. W., Sun, W. W., Wang, H. Y., et al. (2005). Catechol$\mathrm{O}$-methyltransferase gene $\mathrm{Val} / \mathrm{Met}$ functional polymorphism and risk 
of schizophrenia: a large-scale association study plus meta-analysis. Biol. Psychiatry 57, 139-144. doi: 10.1016/j.biopsych.2004.10.018

Fassbender, C., Murphy, K., Foxe, J. J., Wylie, G. R., Javitt, D. C., Robertson, I. H., et al. (2004). A topography of executive functions and their interactions revealed by functional magnetic resonance imaging. Brain Res. Cogn. Brain Res. 20, 132-143. doi: 10.1016/j.cogbrainres.2004.02.007

Fiehler, K., Ullsperger, M., and Von Cramon, D. Y. (2005). Electrophysiological correlates of error correction. Psychophysiology 42, 72-82. doi: 10.1111/j.1469-8986.2005.00265.x

Fitzgerald, K. D., Perkins, S. C., Angstadt, M., Johnson, T., Stern, E. R., Welsh, R. C., et al. (2010). The development of performancemonitoring function in the posterior medial frontal cortex. Neuroimage 49, 3463-3473. doi: 10.1016/j.neuroimage.2009.11.004

Fitzgerald, K. D., Welsh, R. C., Gehring, W. J., Abelson, J. L., Himle, J. A., Liberzon, I., et al. (2005). Error-related hyperactivity of the anterior cingulate cortex in obsessive-compulsive disorder. Biol. Psychiatry 57, 287-294. doi: 10.1016/j.biopsych.2004.10.038

Foong, J., Symms, M. R., Barker, G. J., Maier, M., Miller, D. H., and Ron, M. A. (2002). Investigating regional white matter in schizophrenia using diffusion tensor imaging. Neuroreport 13, 333-336. doi: 10.1097/00001756-20020304000017

Fornito, A., Yung, A. R., Wood, S. J., Phillips, L. J., Nelson, B., Cotton, S., et al. (2008). Anatomic abnormalities of the anterior cingulate cortex before psychosis onset: an MRI study of ultra-high-risk individuals. Biol. Psychiatry 64, 758-765. doi: 10.1016/j.biopsych.2008.05.032

Foti, D., Kotov, R., Bromet, E., and Hajcak, G. (2012). Beyond the broken error-related negativity: functional and diagnostic correlates of error processing in psychosis. Biol. Psychiatry 71, 864-872. doi: 10.1016/j.biopsych.2012.01.007

Frank, M. J., D'Lauro, C., and Curran, T. (2007). Cross-task individual differences in error processing: neural, electrophysiological, and genetic components. Cogn. Affect. Behav. Neurosci. 7, 297-308. doi: 10.3758/CABN.7.4.297

Friso, S., Choi, S. W., Girelli, D., Mason, J. B., Dolnikowski, G. G., Bagley, P. J., et al. (2002). A common mutation in the 5,10-methylenetetrahydrofolate reductase gene affects genomic DNA methylation through an interaction with folate status. Proc. Natl. Acad. Sci. U.S.A. 99, 5606-5611. doi: 10.1073/pnas.062066299

Frosst, P., Blom, H. J., Milos, R., Goyette, P., Sheppard, C. A., Matthews, R. G., et al. (1995). A candidate genetic risk factor for vascular disease: a common mutation in methylenetetrahydrofolate reductase. Nat. Genet. 10, 111-113. doi: 10.1038/ng0595-111

Fujiwara, J., Tobler, P. N., Taira, M., Iijima, T., and Tsutsui, K (2009). Segregated and integrated coding of reward and punishment in the cingulate cortex. J. Neurophysiol. 101, 3284-3293. doi: 10.1152/jn.90909.2008

Garavan, H., Ross, T. J., Murphy, K., Roche, R. A., and Stein, E. A. (2002). Dissociable executive functions in the dynamic control of behavior: inhibition, error detection, and correction. Neuroimage 17, 1820-1829. doi: 10.1006/nimg.2002.1326

Gehring, W. J., and Fencsik, D. E. (2001). Functions of the medial frontal cortex in the processing of conflict and errors. J. Neurosci. 21, 9430-9437.

Gehring, W. J., Goss, B., Coles, M. G., Meyer, D. E., and Donchin, E. (1993). A neural system for error detection and compensation. Psychol. Sci. 4, 385-390. doi: 10.1111/j.14679280.1993.tb00586.x

Gehring, W. J., Himle, J., and Nisenson, L. G. (2000). Actionmonitoring dysfunction in obsessive-compulsive disorder. Psychol. Sci. 11, 1-6. doi 10.1111/1467-9280.00206

Gilbody, S., Lewis, S., and Lightfoot, T. (2007). Methylenetetrahydrofolate reductase (MTHFR) genetic polymorphisms and psychiatric disorders: a HuGE review. Am. J. Epidemiol. 165, 1-13. doi: 10.1093/aje/kwj347

Goldberg, M. C., Spinelli, S., Joel, S., Pekar, J. J., Denckla, M. B., and Mostofsky, S. H. (2011). Children with high functioning autism show increased prefrontal and temporal cortex activity during error monitoring. Dev. Cogn. Neurosci. 1, 47-56. doi: 10.1016/j.den.2010.07.002

Goldberg, T. E., Weinberger, D. R., Berman, K. F., Pliskin, N. H., and Podd, M. H. (1987). Further evidence for dementia of the prefrontal type in schizophrenia? A controlled study of teaching the Wisconsin Card Sorting Test [see comments]. Arch. Gen. Psychiatry 44, 1008-1014. doi: 10.1001/archpsyc.1987.01800230088014

Goldstein, J. M., Goodman, J. M., Seidman, L. J., Kennedy, D N., Makris, N., Lee, H., et al. (1999). Cortical abnormalities in schizophrenia identified by structural magnetic resonance imaging. Arch. Gen. Psychiatry 56, 537-547. doi: 10.1001/archpsyc.56.6.537

Gottesman, I., and Gould, T. D. (2003). The endophenotype concept in psychiatry: etymology and strategic intentions. Am. J. Psychiatry 160, 636-645. doi: 10.1176/appi.ajp.160.4.636

Gould, T. D., and Gottesman, I. I. (2006). Psychiatric endophenotypes and the development of valid animal models. Genes Brain Behav. 5, 113-119. doi: 10.1111/j.1601183X.2005.00186.X

Gratacos, M., Gonzalez, J. R., Mercader, J. M., De Cid, R., Urretavizcaya, M. and Estivill, X. (2007). Brainderived neurotrophic factor Val66Met and psychiatric disorders: meta-analysis of case-control studies confirm association to substance-related disorders, eating disorders, and schizophrenia. Biol. Psychiatry 61, 911-922. doi: 10.1016/j.biopsych.2006.08.025

Groen, Y., Wijers, A. A., Mulder, L. J., Waggeveld, B., Minderaa, R B., and Althaus, M. (2008). Error and feedback processing in children with ADHD and children with Autistic Spectrum Disorder: an EEG event-related potential study. Clin Neurophysiol. 119, 2476-2493. doi: 10.1016/j.clinph.2008.08.004

Ha, T. H., Youn, T., Ha, K. S., Rho K. S., Lee, J. M., Kim, I. Y., et al. (2004). Gray matter abnormalities in paranoid schizophrenia and their clinical correlations. Psychiatry Res. 132, 251-260. doi 10.1016/j.pscychresns.2004.05.001

Hajcak, G., McDonald, N., and Simons, R. F. (2003). To err is autonomic: error-related brain potentials, ANS activity, and post-error compensatory behavior. Psychophysiology 40, 895-903. doi: 10.1111/14698986.00107

Hajcak, G., McDonald, N., and Simons, R. F. (2004). Error-related psychophysiology and negative affect. Brain Cogn. 56, 189-197. doi 10.1016/j.bandc.2003.11.001

Hajcak, G., and Simons, R. F. (2002). Error-related brain activity in obsessive-compulsive undergraduates. Psychiatry Res. 110, 63-72. doi 10.1016/S0165-1781(02)00034-3

Hallett, P. E. (1978). Primary and secondary saccades to goals defined by instructions. Vision Res. 18, 1279-1296. doi: 10.1016/0042-6989(78)90218-3

Hao, Y., Liu, Z., Jiang, T., Gong, G., Liu, H., Tan, L., et al. (2006). White matter integrity of the whole brain is disrupted in firstepisode schizophrenia. Neuroreport 17, 23-26. doi: 10.1097/01.wnr. 0000195664.15090.46

Hariri, A. R., Drabant, E. M., and Weinberger, D. R. (2006). Imaging genetics: perspectives from studies of genetically driven variation in serotonin function and corticolimbic affective processing. Biol. Psychiatry 59, 888-897. doi: 10.1016/j.biopsych. 2005.11.005

Henderson, H., Schwartz, C., Mundy, P., Burnette, C., Sutton, S., Zahka N., et al. (2006). Response monitoring, the error-related negativity, and differences in social behavior in autism. Brain Cogn. 61, 96-109. doi: 10.1016/j.bandc. 2005.12.009

Herrmann, M. J., Rommler, J., Ehlis, A. C., Heidrich, A., and Fallgatter, A. J. (2004). Source localization (LORETA) of the error-related-negativity (ERN/Ne) and positivity (Pe). Brain Res. Cogn. Brain Res. 20, 294-299. doi: 10.1016/j.cogbrainres.2004.02.013

Holroyd, C. B., and Coles, M. G. (2002). The neural basis of human error processing: reinforcement learning, dopamine, and the error-related negativity. Psychol. Rev. 109, 679-709. doi: 10.1037/0033-295X.109.4.679

Holroyd, C. B., Dien, J., and Coles, M. G. (1998). Error-related scalp potentials elicited by hand and foot movements: evidence for an outputindependent error-processing system in humans. Neurosci. Lett. 242, 65-68. doi: 10.1016/S03043940(98)00035-4

Holroyd, C. B., Larsen, J. T., and Cohen, J. D. (2004a). Context dependence of the event-related brain potential associated with reward and punishment. Psychophysiology 41, 245-253. doi: 10.1111/j.1469-8986.2004.00152.x

Holroyd, C. B., Nieuwenhuis, S., Yeung, N., Nystrom, L., Mars, R. B., Coles, M. G., et al. (2004b). Dorsal anterior cingulate cortex shows fMRI response to internal and external error signals. Nat. Neurosci. 7, 497-498. doi: 10.1038/nn1238

Holroyd, C. B., Nieuwenhuis, S., Yeung, N., and Cohen, J. D. (2003). Errors in reward prediction are reflected in the event-related brain potential. Neuroreport 14, 2481-2484. 
doi: 10.1097/00001756-20031219000037

Huang, Y. Y., Battistuzzi, C., Oquendo, M. A., Harkavy-Friedman, J., Greenhill, L., Zalsman, G., et al. (2004). Human 5-HT1A receptor $\mathrm{C}(-1019) \mathrm{G}$ polymorphism and psychopathology. Int. J. Neuropsychopharmacol. 7, 441-451. doi: 10.1017/S1461145704004663

Ikeda, M., Yamanouchi, Y., Kinoshita, Y., Kitajima, T., Yoshimura, R., Hashimoto, S., et al. (2008). Variants of dopamine and serotonin candidate genes as predictors of response to risperidone treatment in first-episode schizophrenia. Pharmacogenomics 9, 1437-1443. doi: 10.2217/14622416.9.10.1437

Imamura, K., Takeshima, T., Nakaso, K., and Nakashima, K. (2007). Homocysteine is toxic for dopaminergic neurons in primary mesencephalic culture. Neuroreport 18, 1319-1322. doi: 10.1097/WNR.0b013e3282aaa0b4

Ito, J., and Kitagawa, J. (2006). Performance monitoring and error processing during a lexical decision task in patients with Parkinson's disease. J. Geriatr. Psychiatry Neurol. 19, 46-54. doi: $10.1177 / 0891988705284716$

Jaber, M., Jones, S., Giros, B., and Caron, M. G. (1997). The dopamine transporter: a crucial component regulating dopamine transmission. Mov. Disord. 12, 629-633. doi: 10.1002/mds.870120502

Jacobson, S., Kelleher, I., Harley, M. Murtagh, A., Clarke, M., Blanchard, M., et al. (2010). Structural and functional brain correlates of subclinical psychotic symptoms in 11-13 year old schoolchildren. Neuroimage 49, 1875-1885. doi: 10.1016/j.neuroimage.2009.09.015

Jansma, J. M., De Zwart, J. A., Van Gelderen, P., Duyn, J. H., Drevets, W. C., and Furey, M. L. (2013). In vivo evaluation of the effect of stimulus distribution on FIR statistical efficiency in event-related fMRI. J. Neurosci. Methods 215, 190-195. doi: 10.1016/j.jneumeth.2013.02.017

Johannes, S., Wieringa, B. M., Nager, W., Rada, D., Dengler, R., Emrich, H. M., et al. (2001). Discrepant target detection and action monitoring in obsessive-compulsive disorder. Psychiatry Res. 108, 101-110. doi: 10.1016/S0925-4927 (01)00117-2

Jonsson, E. G., Nothen, M. M., Grunhage, F., Farde, L., Nakashima, Y., Propping, P., et al. (1999). Polymorphisms in the dopamine
D2 receptor gene and their relationships to striatal dopamine receptor density of healthy volunteers. Mol. Psychiatry 4, 290-296. doi: 10.1038/sj.mp.4000532

Kaczkurkin, A. N. (2013). The effect of manipulating task difficulty on error-related negativity in individuals with obsessive-compulsive symptoms. Biol. Psychol. 93, 122-131. doi: 10.1016/j.biopsycho.2013.01.001

Kanazawa, T., Glatt, S. J., Kia-Keating, B., Yoneda, H., and Tsuang, M. T. (2007). Meta-analysis reveals no association of the Val66Met polymorphism of brain-derived neurotrophic factor with either schizophrenia or bipolar disorder. Psychiatr. Genet. 17, 165-170. doi: 10.1097/YPG.0b013e32801da2e2

Keil, J., Weisz, N., Paul-Jordanov, I., and Wienbruch, C. (2010). Localization of the magnetic equivalent of the ERN and induced oscillatory brain activity. Neuroimage 51, 404-411. doi: 10.1016/j.neuroimage.2010.02.003

Kerns, J. G., Cohen, J. D., Macdonald, A. W. 3rd., Cho, R. Y., Stenger, V. A., and Carter, C. S. (2004). Anterior cingulate conflict monitoring and adjustments in control. Science 303, 1023-1026. doi: 10.1126/ science. 1089910

Kerns, J. G., Cohen, J. D., Macdonald, A. W. 3rd., Johnson, M. K., Stenger, V. A., Aizenstein, H., et al. (2005). Decreased conflictand error-related activity in the anterior cingulate cortex in subjects with schizophrenia. Am. J. Psychiatry 162, 1833-1839. doi: 10.1176/appi.ajp.162.10.1833

Kim, M. S., Kang, S. S., Shin, K. S., Yoo, S. Y., Kim, Y. Y., and Kwon, J. S. (2006). Neuropsychological correlates of error negativity and positivity in schizophrenia patients. Psychiatry Clin. Neurosci. 60, 303-311. doi: 10.1111/j.1440-1819.2006.01506.x

Kishi, T., Okochi, T., Tsunoka, T., Okumura, T., Kitajima, T., Kawashima, K., et al. (2011) Serotonin 1A receptor gene, schizophrenia and bipolar disorder: an association study and metaanalysis. Psychiatry Res. 185, 20-26. doi: 10.1016/j.psychres.2010.06.003

Klein, T. A., Endrass, T., Kathmann, N., Neumann, J., Von Cramon, D. Y., and Ullsperger, M. (2007a). Neural correlates of error awareness. Neuroimage 34, 1774-1781. doi: 10.1016/j.neuroimage.2006.11.014

Klein, T. A., Neumann, J., Reuter, M., Hennig, J., Von Cramon, D. Y., and
Ullsperger, M. (2007b). Genetically determined differences in learning from errors. Science 318, 1642-1645. doi: 10.1126/science.1145044

Klunk, W. E. (2011). Amyloid imaging as a biomarker for cerebral betaamyloidosis and risk prediction for Alzheimer dementia. Neurobiol. Aging 32(Suppl. 1), S20-S36. doi: 10.1016/j.neurobiolaging.2011. 09.006

Kopp, B., and Rist, F. (1994) Error-correcting behavior in schizophrenic patients. Schizophr. Res. 13, 11-22. doi: 10.1016/0920-9964(94)90056-6

Kopp, B., and Rist, F. (1999). An eventrelated brain potential substrate of disturbed response monitoring in paranoid schizophrenic patients. J. Abnorm. Psychol. 108, 337-346. doi: 10.1037/0021-843X.108.2.337

Kramer, U. M., Cunillera, T. Camara, E., Marco-Pallares, J., Cucurell, D., Nager, W. et al. (2007). The impact of catechol-O-methyltransferase and dopamine D4 receptor genotypes on neurophysiological markers of performance monitoring. J. Neurosci. 27, 14190-14198. doi 10.1523/JNEUROSCI.4229-07.2007

Kubicki, M., Westin, C. F., Nestor, P. G. Wible, C. G., Frumin, M., Maier, S. E., et al. (2003). Cingulate fasciculus integrity disruption in schizophrenia: a magnetic resonance diffusion tensor imaging study. Biol. Psychiatry 54, 1171-1180. doi: 10.1016/S0006-3223(03)00419-0

Kuperberg, G. R., Broome, M. R. McGuire, P. K., David, A. S. Eddy, M., Ozawa, F., et al. (2003) Regionally localized thinning of the cerebral cortex in schizophrenia. Arch. Gen. Psychiatry 60, 878-888. doi: 10.1001/archpsyc.60.9.878

Kwon, J. S., Kim, E., Kang, D. H. Choi, J. S., Yu, K. S., Jang, I. J., et al. (2008). Taq1A polymorphism in the dopamine D2 receptor gene as a predictor of clinical response to aripiprazole. Eur. Neuropsychopharmacol. 18, 897-907. doi: 10.1016/j.euroneuro. 2008.07.010

Kyriakopoulos, M., Dima, D., Roiser, J. P., Corrigall, R., Barker, G. J. and Frangou, S. (2012). Abnormal functional activation and connectivity in the working memory network in early-onset schizophrenia. J. Am. Acad. Child. Adolesc Psychiatry 51, 911-920 e912. doi: 10.1016/j.jaac.2012.06.020

Ladouceur, C. D., Dahl, R. E., and Carter, C. S. (2007). Development of action monitoring through adolescence into adulthood: ERP and source localization. Dev. Sci. 10, 874-891. doi: 10.1111/j.1467-7687.2007.00639.x

Laurens, K. R., Hodgins, S., Mould, G. L., West, S. A., Schoenberg, P. L., Murray, R. M., et al. (2010). Error-related processing dysfunction in children aged 9 to 12 years presenting putative antecedents of schizophrenia. Biol. Psychiatry 67, 238-245. doi: 10.1016/j.biopsych.2009.07.030

Laurens, K. R., Ngan, E. T., Bates, A. T., Kiehl, K. A., and Liddle, P. F. (2003). Rostral anterior cingulate cortex dysfunction during error processing in schizophrenia. Brain 126, 610-622. doi: 10.1093/brain/awg056

Lemonde, S., Turecki, G., Bakish, D., Du, L., Hrdina, P. D., Bown, C. D. et al. (2003). Impaired repression at a 5-hydroxytryptamine $1 \mathrm{~A}$ receptor gene polymorphism associated with major depression and suicide. J. Neurosci. 23, 8788-8799.

Levy, D. L., Mendell, N. R., Lavancher, C. A., Brownstein, J., Krastoshevsky, O., Teraspulsky, L., et al. (1998). "Disinhibition in antisaccade performance in schizophrenia," in Origins and Development of Schizophrenia, eds M. F. Lenzenweger and R. H. Dworkin (Washington, DC: American Psychological Association), 185-210. doi: 10.1037/10305-007

Li, C. S., Yan, P., Bergquist, K. L., and Sinha, R. (2007). Greater activation of the "default" brain regions predicts stop signal errors. Neuroimage 38, 640-648. doi: 10.1016/j.neuroimage.2007.07.021

Liu, Y., Gehring, W. J., Weissman, D. H., Taylor, S. F., and Fitzgerald, K. D. (2012). Trial-by-trial adjustments of cognitive control following errors and response conflict are altered in pediatric obsessive compulsive disorder. Front. Psychiatry 3:41. doi: 10.3389/fpsyt.2012.00041

Logan, G. D., and Cowan, W. B. (1984). On the ability to inhibit thought and action: a theory of an act of control. Psychol. Rev. 91, 295-327. doi: 10.1037/0033-295X.91.3.295

Luo, X., Zhang, S., Hu, S., Bednarski, S. R., Erdman, E., Farr, O. M., et al. (2013). Error processing and gender-shared and -specific neural predictors of relapse in cocaine dependence. Brain 136, 1231-1244. doi: 10.1093/brain/awt040

Lutz, U. C. (2008). Alterations in homocysteine metabolism among alcohol dependent patientsclinical, pathobiochemical and 
genetic aspects. Curr. Drug Abuse. Rev. 1, 47-55. doi: 10.2174/1874473710801010047

Lutz, U. C., Batra, A., Kolb, W., Machicao, F., Maurer, S., and Kohnke, M. D. (2006). Methylenetetrahydrofolate reductase C677T-polymorphism and its association with alcohol withdrawal seizure. Alcohol. Clin. Exp. Res. 30, 1966-1971. doi: 10.1111/j.1530-0277.2006.00242.x

Lutz, U. C., Batra, A., Wiatr, G., Machicao, F., Kolb, W., Maurer, S., et al. (2007). Significant impact of MTHFR C677T polymorphism on plasma homovanillic acid (HVA) levels among alcohol-dependent patients. Addict. Biol. 12, 100-105. doi: 10.1111/j.1369-1600.2006.00046.x

Luu, P., Tucker, D. M., Derryberry, D., Reed, M., and Poulsen, C. (2003). Electrophysiological responses to errors and feedback in the process of action regulation. Psychol. Sci. 14, 47-53. doi: 10.1111/14679280.01417

Malenka, R. C., Angel, R. W., Hampton, B., and Berger, P. A. (1982). Impaired central error-correcting behavior in schizophrenia. Arch. Gen. Psychiatry 39, 101-107. doi: 10.1001/archpsyc.1982.04290010073013

Malenka, R. C., Angel, R. W., Thiemann, S., Weitz, C. J., and Berger, P. A. (1986). Central error-correcting behavior in schizophrenia and depression. Biol. Psychiatry 21, 263-273. doi: 10.1016/0006-3223(86)90047-8

Maltby, N., Tolin, D. F., Worhunsky, P., O'Keefe, T. M., and Kiehl, K. A. (2005). Dysfunctional action monitoring hyperactivates frontal-striatal circuits in obsessive-compulsive disorder: an event-related fMRI study. Neuroimage 24, 495-503. doi: 10.1016/j.neuroimage.2004.08.041

Manoach, D. S., Greve, D. N., Lindgren, K. A., and Dale, A. M. (2003). Identifying regional activity associated with temporally separated components of working memory using event-related functional MRI. Neuroimage 20, 1670-1684. doi: 10.1016/j.neuroimage.2003.08.002

Manoach, D. S., Ketwaroo, G. A., Polli, F. E., Thakkar, K. N., Barton, J. J., Goff, D. C., et al. (2007). Reduced microstructural integrity of the white matter underlying anterior cingulate cortex is associated with increased saccadic latency in schizophrenia. Neuroimage 37, 599-610. doi: 10.1016/j.neuroimage.2007.04.062
Mathalon, D. H., Fedor, M., Faustman, W. O., Gray, M., Askari, N., and Ford, J. M. (2002). Response-monitoring dysfunction in schizophrenia: an event-related brain potential study. J. Abnorm. Psychol. 111, 22-41. doi: 10.1037/0021-843X.111.1.22

Mathews, C. A., Perez, V. B., Delucchi, K. L., and Mathalon, D. H. (2012). Error-related negativity in individuals with obsessive-compulsive symptoms: toward an understanding of hoarding behaviors. Biol. Psychol. 89, 487-494. doi: 10.1016/j.biopsycho.2011.12.018

McCoy, A. N., Crowley, J. C., Haghighian, G., Dean, H. L. and Platt, M. L. (2003). Saccade reward signals in posterior cingulate cortex. Neuron 40, 1031-1040. doi: 10.1016/S0896-6273(03)00719-0

McDonald, C., Bullmore, E., Sham, P., Chitnis, X., Suckling, J., Maccabe, J., et al. (2005). Regional volume deviations of brain structure in schizophrenia and psychotic bipolar disorder: computational morphometry study. Br. J. Psychiatry 186, 369-377. doi: 10.1192/bjp. 186.5.369

Menon, V., Adleman, N. E., White, C. D., Glover, G. H., and Reiss, A. L. (2001). Error-related brain activation during a Go/NoGo response inhibition task. Hum. Brain Mapp. 12, 131-143.

Meyer, A., Klein, D. N., Torpey, D. C., Kujawa, A. J., Hayden, E. P., Sheikh, H. I., et al. (2012). Additive effects of the dopamine D2 receptor and dopamine transporter genes on the error-related negativity in young children. Genes Brain Behav. 11, 695-703. doi: 10.1111/j.1601183X.2012.00812.x

Meyer-Lindenberg, A., Kohn, P. D, Kolachana, B., Kippenhan, S., McInerney-Leo, A., Nussbaum, R., et al. (2005). Midbrain dopamine and prefrontal function in humans: interaction and modulation by COMT genotype. Nat. Neurosci. 8, 594-596. doi: 10.1038/nn1438

Mitelman, S. A., Shihabuddin, L., Brickman, A. M., Hazlett, E. A., and Buchsbaum, M. S. (2005). Volume of the cingulate and outcome in schizophrenia. Schizophr. Res. 72, 91-108. doi: 10.1016/j.schres.2004.02.011

Morgan, L., Wetherby, A. M., and Barber, A. (2008). Repetitive and stereotyped movements in children with autism spectrum disorders late in the second year of life. J. Child Psychol. Psychiatry 49, 826-837. doi: 10.1111/j.1469-7610.2008.01904.x
Morris, S. E., Yee, C. M., and Nuechterlein, K. H. (2006). Electrophysiological analysis of error monitoring in schizophrenia. J. Abnorm. Psychol. 115, 239-250. doi: 10.1037/0021-843X.115.2.239

Mossner, R., Schuhmacher, A., Kuhn, K. U., Cvetanovska, G., Rujescu, D., Zill, P., et al. (2009). Functional serotonin 1A receptor variant influences treatment response to atypical antipsychotics in schizophrenia. Pharmacogenet. Genom. 19, 91-94. doi 10.1097/FPC.0b013e328311a917

Munafo, M. R., Bowes, L., Clark, T. G., and Flint, J. (2005). Lack of association of the COMT (Val158/108 Met) gene and schizophrenia: a meta-analysis of case-control studies. Mol. Psychiatry 10, 765-770 doi: 10.1038/sj.mp.4001664

Nieuwenhuis, S., Nielen, M. M., Mol, N., Hajcak, G., and Veltman, D. J. (2005). Performance monitoring in obsessive-compulsive disorder. Psychiatry Res. 134, 111-122. doi: 10.1016/j.psychres.2005.02.005

Nieuwenhuis, S., Ridderinkhof, K. R., Blom, J., Band, G. P., and Kok, A. (2001). Error-related brain potentials are differentially related to awareness of response errors: evidence from an antisaccade task. Psychophysiology 38, 752-760. doi: 10.1111/1469-8986.3850752

Nieuwenhuis, S., Yeung, N., Van Den Wildenberg, W., and Ridderinkhof, K. R. (2003). Electrophysiological correlates of anterior cingulate function in a go/no-go task: effects of response conflict and trial type frequency. Cogn. Affect. Behav. Neurosci. 3, 17-26. doi: 10.3758/CABN.3.1.17

Noriuchi, M., Kikuchi, Y., Yoshiura, T., Kira, R., Shigeto, H., Hara, T., et al. (2010). Altered white matter fractional anisotropy and social impairment in children with autism spectrum disorder. Brain Res. 1362, 141-149. doi 10.1016/j.brainres.2010.09.051

Ohnuma, T., Kimura, M., Takahashi, T., Iwamoto, N., and Arai, H. (1997). A magnetic resonance imaging study in first-episode disorganizedtype patients with schizophrenia. Psychiatry Clin. Neurosci. 51, 9-15. doi: 10.1111/j.14401819.1997.tb02359.x

Okamura, N., and Reinscheid, R. K. (2007). Neuropeptide S: a novel modulator of stress and arousal. Stress 10, 221-226. doi: 10.1080/10253890701248673

Okochi, T., Ikeda, M., Kishi, T., Kawashima, K., Kinoshita, Y.,
Kitajima, T., et al. (2009). Metaanalysis of association between genetic variants in COMT and schizophrenia: an update. Schizophr. Res. 110, 140-148. doi: 10.1016/j.schres.2009.02.019

Okuyama, Y., Ishiguro, H., Toru, M., and Arinami, T. (1999). A genetic polymorphism in the promoter region of DRD4 associated with expression and schizophrenia. Biochem. Biophys. Res. Commun. 258, 292-295. doi: 10.1006/bbrc. 1999.0630

Olvet, D. M., and Hajcak, G. (2008) The error-related negativity (ERN) and psychopathology: toward an endophenotype. Clin. Psychol. Rev. 28, 1343-1354. doi: 10.1016/j.cpr.2008.07.003

Olvet, D. M., Hatchwell, E., and Hajcak, G. (2010). Lack of association between the 5-HTTLPR and the error-related negativity (ERN). Biol. Psychol. 85, 504-508. doi: 10.1016/j.biopsycho.2010.09.012

Osinsky, R., Hewig, J., Alexander, N., and Hennig, J. (2012). COMT Val158Met genotype and the common basis of error and conflict monitoring. Brain Res. 1452, 108-118. doi: 10.1016/j.brainres.2012.02.054

Overbeek, T. J. M., Nieuwenhuis, S., and Ridderinkhof, K. R. (2005). Dissociable components of error processing. J. Psychophysiol. 19, 319-329. doi: 10.1027/0269-8803.19.4.319

Parsons, M. J., Mata, I., Beperet, M., Iribarren-Iriso, F., Arroyo, B., Sainz, R., et al. (2007). A dopamine D2 receptor gene-related polymorphism is associated with schizophrenia in a Spanish population isolate. Psychiatr. Genet. 17, 159-163. doi 10.1097/YPG.0b013e328017f8a4

Paus, T., Petrides, M., Evans, A. C., and Meyer, E. (1993). Role of the human anterior cingulate cortex in the control of oculomotor, manual, and speech responses: a positron emission tomography study. J. Neurophysiol. 70, 453-469.

Perez, V. B., Ford, J. M., Roach, B. J., Woods, S. W., McGlashan, T. H., Srihari, V. H., et al. (2012). Error monitoring dysfunction across the illness course of schizophrenia. J. Abnorm. Psychol. 121, 372-387. doi: 10.1037/a0025487

Pezawas, L., Meyer-Lindenberg, A., Drabant, E. M., Verchinski, B. A., Munoz, K. E., Kolachana, B. S., et al. (2005). 5-HTTLPR polymorphism impacts human cingulate-amygdala interactions: a genetic susceptibility mechanism for depression. 
Nat. Neurosci. 8, 828-834. doi: 10.1038/nn1463

Phillips, M. L., Drevets, W. C., Rauch, S. L., and Lane, R. (2003). Neurobiology of emotion perception I: the neural basis of normal emotion perception. Biol. Psychiatry 54, 504-514. doi: 10.1016/S0006-3223(03)00168-9

Pitman, R. K. (1987). A cybernetic model of obsessive-compulsive psychopathology. Comp. Psychiatry 28, 334-343. doi: 10.1016/0010440X (87)90070-8

Pohjalainen, T., Rinne, J. O., Nagren, K., Lehikoinen, P., Anttila, K., Syvalahti, E. K., et al. (1998). The Al allele of the human D2 dopamine receptor gene predicts low D2 receptor availability in healthy volunteers. Mol. Psychiatry 3, 256-260. doi: 10.1038/sj.mp.4000350

Polli, F. E., Barton, J. J., Cain, M. S., Thakkar, K. N., Rauch, S. L., and Manoach, D. S. (2005). Rostral and dorsal anterior cingulate cortex make dissociable contributions during antisaccade error commission. Proc. Natl. Acad. Sci. U.S.A. 102, 15700-15705. doi: $10.1073 /$ pnas.0503657102

Polli, F. E., Barton, J. J., Thakkar, K. N., Greve, D. N., Goff, D. C., Rauch, S. L., et al. (2008). Reduced error-related activation in two anterior cingulate circuits is related to impaired performance in schizophrenia. Brain 131, 971-986. doi: 10.1093/brain/awm307

Polli, F. E., Barton, J. J., Vangel, M., Goff, D. C., Iguchi, L., and Manoach, D. S. (2006). Schizophrenia patients show intact immediate error-related performance adjustments on an antisaccade task. Schizophr. Res. 82, 191-201. doi: 10.1016/j.schres.2005.10.003

Polli, F. E., Wright, C. I., Milad, M. R., Dickerson, B. C., Vangel, M., Barton, J. J. S., et al. (2009). Hemispheric differences in amygdala contributions to response monitoring. Neuroreport 20, 398-402. doi: 10.1097/WNR.0b013e328324edb8

Purcell, S. M., Wray, N. R., Stone, J. L., Visscher, P. M., O'Donovan, M. C., Sullivan, P. F., et al. (2009). Common polygenic variation contributes to risk of schizophrenia and bipolar disorder. Nature 460, 748-752.

Rabbitt, P. M. (1966). Errors and error correction in choice-response tasks. J. Exp. Psychol. 71, 264-272. doi: 10.1037/h0022853

Radant, A. D., Dobie, D. J., Calkins, M. E., Olincy, A., Braff, D. L.
Cadenhead, K. S., et al. (2010). Antisaccade performance in schizophrenia patients, their firstdegree biological relatives, and community comparison subjects: data from the COGS study. Psychophysiology 47, 846-856.

Raichle, M. E., Macleod, A. M., Snyder, A. Z., Powers, W. J., Gusnard, D. A., and Shulman, G. L. (2001). A default mode of brain function. Proc. Natl. Acad. Sci. U.S.A. 98, 676-682. doi: 10.1073/pnas.98.2.676

Reinscheid, R. K., Xu, Y. L., Okamura, N., Zeng, J., Chung, S., Pai, R., et al. (2005). Pharmacological characterization of human and murine neuropeptide $s$ receptor variants. J. Pharmacol. Exp. Therapeut. 315, 1338-1345. doi: 10.1124/jpet.105.093427

Reynolds, G. P., Arranz, B. Templeman, L. A., Fertuzinhos, S., and San, L. (2006). Effect of 5-HT1A receptor gene polymorphism on negative and depressive symptom response to antipsychotic treatment of drugnaive psychotic patients. Am. J. Psychiatry 163, 1826-1829. doi: 10.1176/appi.ajp.163.10.1826

Ridderinkhof, K. R., Nieuwenhuis, S., and Bashore, T. R. (2003). Errors are foreshadowed in brain potentials associated with action monitoring in cingulate cortex in humans. Neurosci. Lett. 348, 1-4. doi: 10.1016/S0304-3940(03)00566-4

Ridderinkhof, K. R., Ullsperger, M., Crone, E. A., and Nieuwenhuis, S. (2004). The role of the medial frontal cortex in cognitive control. Science 306, 443-447. doi: 10.1126/science. 1100301

Ritchie, T., and Noble, E. P. (2003). Association of seven polymorphisms of the D2 dopamine receptor gene with brain receptor-binding characteristics. Neurochem. Res. 28, 73-82. doi: 10.1023/A:1021648128758

Roffman, J. L., Brohawn, D. G., Friedman, J., Dyckman, K. A., Thakkar, K. N., Agam, Y., et al. (2011a). MTHFR 677C $>$ T effects on anterior cingulate structure and function during response monitoring in schizophrenia: a preliminary study. Brain Imaging Behav. 5, 65-75. doi: 10.1007/s11682-010-9111-2

Roffman, J. L., Nitenson, A. Z., Agam, Y., Isom, M., Friedman, J. S., Dyckman, K. A., et al. (2011b). A hypomethylating variant of MTHFR, 677C $>$ T, blunts the neural response to errors in patients with schizophrenia and healthy individuals. PLoS ONE 6:e25253. doi: 10.1371/journal.pone.0025253

Roffman, J. L., Gollub, R. L., Calhoun, V. D., Wassink, T. H., Weiss, A. P., Ho, B. C., et al. (2008a). MTHFR $677 \mathrm{C} \Rightarrow \mathrm{T}$ genotype disrupts prefrontal function in schizophrenia through an interaction with COMT 158Val $\Rightarrow$ Met. Proc. Natl. Acad. Sci. U.S.A. 105, 17573-17578. doi 10.1073/pnas.0803727105

Roffman, J. L., Weiss, A. P. Deckersbach, T., Freudenreich, O., Henderson, D. C., Wong, D. H., et al. (2008b). Interactive effects of COMT Val108/158Met and MTHFR C677T on executive function in schizophrenia. Am. J. Med. Genet. B Neuropsychiatr. Genet. 147B, 990-995. doi: 10.1002/ajmg.b.30684

Roffman, J. L., Weiss, A. P., Purcell, S. Caffalette, C. A., Freudenreich, O. Henderson, D. C., et al. (2008c). Contribution of methylenetetrahydrofolate reductase (MTHFR) polymorphisms to negative symptoms in schizophrenia. Biol. Psychiatry 63, 42-48. doi: 10.1016/j.biopsych.2006.12.017

Ruchsow, M., Spitzer, M., Gron, G. Grothe, J., and Kiefer, M. (2005) Error processing and impulsiveness in normals: evidence from event-related potentials. Brain Res. Cogn. Brain Res. 24, 317-325. doi: 10.1016/j.cogbrainres.2005.02.003

Russell, J., and Jarrold, C. (1998) Error-correction problems in autism: evidence for a monitoring impairment? J. Autism Dev. Disord. 28, 177-188. doi: 10.1023/A:1026009203333

Sandrone, S. (2012). The brain as a crystal ball: the predictive potential of default mode network. Front. Hum. Neurosci. 6:261. doi: 10.3389/fnhum.2012.00261

Santesso, D. L., Drmic, I. E., Jetha M. K., Bryson, S. E., Goldberg, J. O., Hall, G. B., et al. (2011). An event-related source localization study of response monitoring and social impairments in autism spectrum disorder. Psychophysiology 241-251. doi: 10.1111/j.1469-8986.2010.01056.x

Santesso, D. L., Segalowitz, S. J., and Schmidt, L. A. (2006). Errorrelated electrocortical responses are enhanced in children with obsessive-compulsive behaviors. Dev. Neuropsychol. 29, 431-445. doi: 10.1207/s15326942dn2903_3

Scheffers, M. K., and Coles, M. G. (2000). Performance monitoring in a confusing world: errorrelated brain activity, judgments of response accuracy, and types of errors. J. Exp. Psychol. Hum. Percept. Perform. 26, 141-151. doi: 10.1037/0096-1523.26.1.141

Schmahmann, J. D., Pandya, D. N., Wang, R., Dai, G., D’Arceuil, H. E., De Crespigny, A. J., et al. (2007). Association fibre pathways of the brain: parallel observations from diffusion spectrum imaging and autoradiography. Brain 130, 630-653. doi: 10.1093/brain/awl359

Schultz, W. (2002). Getting formal with dopamine and reward. Neuron 36, 241-263. doi: 10.1016/S08966273(02)00967-4

Schultz, W., Dayan, P., and Montague, P. R. (1997). A neural substrate of prediction and reward. Science 275, 1593-1598. doi: 10.1126/science.275.5306.1593

Shi, J., Gershon, E. S., and Liu, C. (2008). Genetic associations with schizophrenia: metaanalyses of 12 candidate genes. Schizophr. Res. 104, 96-107. doi: 10.1016/j.schres.2008.06.016

Sigmundsson, T., Suckling, J., Maier, M., Williams, S., Bullmore, E., Greenwood, K., et al. (2001). Structural abnormalities in frontal, temporal, and limbic regions and interconnecting white matter tracts in schizophrenic patients with prominent negative symptoms. Am. J. Psychiatry 158, 234-243. doi: 10.1176/appi.ajp.158.2.234

Simmonite, M., Bates, A. T., Groom, M. J., Jackson, G. M., Hollis, C., and Liddle, P. F. (2012). Error processing-associated eventrelated potentials in schizophrenia and unaffected siblings. Int. J. Psychophysiol. 84, 74-79. doi: 10.1016/j.ijpsycho.2012.01.012

Simon, J. R. (1969). Reactions towards the source of stimulation. J. Exp. Psychol. 81, 174-176. doi: 10.1037/h0027448

Smith, B. W., Mitchell, D. G., Hardin, M. G., Jazbec, S., Fridberg, D., Blair, R. J., et al. (2009). Neural substrates of reward magnitude, probability, and risk during a wheel of fortune decision-making task. Neuroimage 44, 600-609. doi: 10.1016/j.neuroimage.2008. 08.016

Sokhadze, E., Baruth, J., El-Baz, A., Horrell, T., Sokhadze, G., Carroll, T., et al. (2010). Impaired error monitoring and correction function in autism. J. Neurother. 14, 79-95. doi: 10.1080/10874201003771561

Sokhadze, E. M., Baruth, J. M., Sears, L., Sokhadze, G. E., El-Baz, A. S., and Casanova, M. F. (2012a). Prefrontal neuromodulation using rTMS improves error monitoring and correction function in autism. 
Appl. Psychophysiol. Biofeed. 37, 91-102. doi: 10.1007/s10484-0129182-5

Sokhadze, E. M., Baruth, J. M., Sears, L., Sokhadze, G. E., El-Baz, A. S., Williams, E., et al. (2012b). event-related potential study of attention regulation during illusory figure categorization task in adhd, autism spectrum disorder, and typical children. J. Neurother. 16, 12-31. doi: 10.1080/10874208. 2012.650119

South, M., Larson, M. J., Krauskopf, E., and Clawson, A. (2010). Error processing in high-functioning Autism Spectrum Disorders. Biol. Psychol. 85, 242-251. doi: 10.1016/j.biopsycho.2010.07.009

Stroop, J. R. (1935). Studies of interference in serial verbal reaction. J. Exp. Psychol. 18, 643-662. doi: 10.1037/h0054651

Summerfelt, A. T., Alphs, L. D., Wagman, A. M., Funderburk, F. R., Hierholzer, R. M., and Strauss, M. E. (1991). Reduction of perseverative errors in patients with schizophrenia using monetary feedback. J. Abnorm. Psychol. 100, 613-616. doi: 10.1037/0021-843X.100.4.613

Sun, Z., Wang, F., Cui, L., Breeze, J., Du, X., Wang, X., et al. (2003). Abnormal anterior cingulum in patients with schizophrenia: a diffusion tensor imaging study. Neuroreport 14, 1833-1836. doi: 10.1097/00001756-20031006000015

Suzuki, M., Nohara, S., Hagino, H., Kurokawa, K., Yotsutsuji, T., Kawasaki, Y., et al. (2002). Regional changes in brain gray and white matter in patients with schizophrenia demonstrated with voxel-based analysis of MRI. Schizophr. Res. 55, 41-54. doi: 10.1016/S0920-9964(01)00224-9

Taj, M. J. R., Viswanath, B., Purushottam, M., Kandavel, T., Janardhan Reddy, Y. C., and Jain, S. (2013). DRD4 gene and obsessive compulsive disorder: do symptom dimensions have specific genetic correlates? Prog. Neuropsychopharmacol. Biol. Psychiatry 41, 18-23. doi: 10.1016/i.pnpbp.2012.10.023

Tan, H. Y., Callicott, J. H., and Weinberger, D. R. (2008). Intermediate phenotypes in schizophrenia genetics redux: is it a no brainer? Mol. Psychiatry 13, 233-238. doi: 10.1038/sj.mp.4002145

Taylor, S. F., Martis, B., Fitzgerald, K. D., Welsh, R. C., Abelson, J. L., Liberzon, I., et al. (2006). Medial frontal cortex activity and loss-related responses to errors. J. Neurosci. 26, 4063-4070. doi: 10.1523/JNEUROSCI.4709-05.2006

Taylor, S. F., Stern, E. R., and Gehring, W. J. (2007). Neural systems for error monitoring: recent findings and theoretical perspectives. Neuroscientist 13, 160-172. doi: $10.1177 / 1073858406298184$

Thakkar, K. N., Polli, F. E., Joseph, R. M., Tuch, D. S., Hadjikhani, N., Barton, J. J., et al. (2008). Response monitoring, repetitive behaviour and anterior cingulate abnormalities in autism spectrum disorders (ASD). Brain 131, 2464-2478. doi: 10.1093/brain/awn099

Thorndike, E. (1911). Animal Intelligence. New York, NY: Macmillan.

Tu, P., Buckner, R. L., Zollei, L., Dyckman, K. A., and Manoach, D. S. (2010). Reduced functional connectivity in a right-hemisphere network for volitional ocular motor control in schizophrenia. Brain 133, 625-637. doi: 10.1093/brain/awp317

Turetsky, B. I., Greenwood, T. A., Olincy, A., Radant, A. D., Braff, D. L., Cadenhead, K. S., et al. (2008). Abnormal auditory N100 amplitude: a heritable endophenotype in first-degree relatives of schizophrenia probands. Biol. Psychiatry 64, 1051-1059. doi: 10.1016/j.biopsych.2008.06.018

Turken, A. U., Vuilleumier, P., Mathalon, D. H., Swick, D., and Ford, J. M. (2003). Are impairments of action monitoring and executive control true dissociative dysfunctions in patients with schizophrenia? Am J. Psychiatry 160, 1881-1883. doi: 10.1176/appi.ajp.160.10.1881

Ursu, S., Stenger, V. A., Shear, M. K., Jones, M. R., and Carter, C. S. (2003). Overactive action monitoring in obsessive-compulsive disorder: evidence from functional magnetic resonance imaging. Psychol. Sci. 14, 347-353. doi: 10.1111/14679280.24411

Van Boxtel, G. J. M., Van Der Molen, M. W., and Jennings, J. R. (2005). Differential involvement of the anterior cingulate cortex in performance monitoring during a stop-signal task. J. Psychophysiol. 19, 1-10. doi: 10.1027/0269-8803.19.1.1

Van De Giessen, E., De Win, M. M., Tanck, M. W., Van Den Brink, W., Baas, F., and Booij, J. (2009). Striatal dopamine transporter availability associated with polymorphisms in the dopamine transporter gene SLC6A3. J. Nuclear Med. 50, $45-52$.
Vandenbergh, D. J., Persico, A. M., Hawkins, A. L., Griffin, C. A. Li, X., Jabs, E. W., et al. (1992). Human dopamine transporter gene (DAT1) maps to chromosome 5 p15.3 and displays a VNTR. Genomics 14, 1104-1106. doi: 10.1016/S0888-7543(05)80138-7

Van Dyck, C. H., Malison, R. T., Jacobsen, L. K., Seibyl, J. P., Staley, J. K., Laruelle, M., et al. (2005). Increased dopamine transporter availability associated with the 9-repeat allele of the SLC6A3 gene. J. Nuclear Med. 46, 745-751.

Van Hoesen, G. W., Morecraft, R. J., and Vogt, B. A. (1993). "Connections of the monkey cingulate cortex," in Neurobiology of Cingulate Cortex and Limbic Thalamus: A Comprehensive Handbook, eds B. A. Vogt and M. Gabriel (Boston, MA: Birkhauser), 249-284.

Van Schie, H. T., Mars, R. B., Coles, M. G., and Bekkering, H. (2004). Modulation of activity in medial frontal and motor cortices during error observation. Nat. Neurosci. 7 , 549-554. doi: 10.1038/nn1239

Van Tol, H. H., Wu, C. M., Guan, H. C. Ohara, K., Bunzow, J. R., Civelli, O. et al. (1992). Multiple dopamine D4 receptor variants in the human population. Nature 358, 149-152. doi: $10.1038 / 358149 \mathrm{a} 0$

Van Veen, V., and Carter, C. S. (2002). The timing of actionmonitoring processes in the anterior cingulate cortex. J. $\operatorname{Cog} n$. Neurosci. 14, 593-602. doi 10.1162/08989290260045837

Van 'T Ent, D., and Apkarian, P. (1999). Motoric response inhibition in finger movement and saccadic eye movement: a comparative study. Clin. Neurophysiol. 110, 1058-1072. doi: $\quad 10.1016 / S 1388-2457(98)$ 00036-4

Vlamings, P. H., Jonkman, L. M., Hoeksma, M. R., Van Engeland, H., and Kemner, C. (2008). Reduced error monitoring in children with autism spectrum disorder: an ERP study. Eur. J. Neurosci. 28, 399-406. doi: 10.1111/j.1460-9568.2008.06336.x

Waltz, J. A., Frank, M. J., Robinson, B. M., and Gold, J. M. (2007). Selective reinforcement learning deficits in schizophrenia support predictions from computational models of striatal-cortical dysfunction. Biol. Psychiatry 62, 756-764. doi: $\quad$ 10.1016/j.biopsych.2006 09.042

Waltz, J. A., and Gold, J. M. (2007). Probabilistic reversal learning impairments in schizophrenia: further evidence of orbitofrontal dysfunction. Schizophr. Res. 93, 296-303. doi: 10.1016/j.schres.2007. 03.010

Waltz, J. A., Schweitzer, J. B., Ross, T. J., Kurup, P. K., Salmeron, B. J., Rose, E. J., et al. (2010). Abnormal responses to monetary outcomes in cortex, but not in the basal ganglia, in schizophrenia. Neuropsychopharmacology 35, 2427-2439. doi: 10.1038/npp. 2010.126

Wang, F., Sun, Z., Cui, L., Du, X., Wang, X., Zhang, H., et al. (2004). Anterior cingulum abnormalities in male patients with schizophrenia determined through diffusion tensor imaging. Am. J. Psychiatry 161, 573-575. doi: 10.1176/appi.ajp.161.3.573

Watt, N., Wetherby, A. M., Barber, A., and Morgan, L. (2008). Repetitive and stereotyped behaviors in children with autism spectrum disorders in the second year of life. J. Autism. Dev. Disord. 38, 1518-1533. doi 10.1007/s10803-007-0532-8

Whalen, P. J., Bush, G., McNally, R. J., Wilhelm, S., McInerney, S. C., Jenike, M. A., et al. (1998). The emotional counting Stroop paradigm: a functional magnetic resonance imaging probe of the anterior cingulate affective division. Biol. Psychiatry 44, 1219-1228. doi: 10.1016/S0006-3223(98)00251-0

Whalley, H. C., Simonotto, E., Moorhead, W., McIntosh, A., Marshall, I., Ebmeier, K. P., et al. (2006). Functional imaging as a predictor of schizophrenia. Biol. Psychiatry 60, 454-462. doi: 10.1016/j.biopsych.2005.11.013

Whitfield-Gabrieli, S., and Ford, J. M. (2012). Default mode network activity and connectivity in psychopathology. Annu. Rev. Clin. Psychol. 8, 49-76. doi: 10.1146/ annurev-clinpsy-032511-143049

Willemssen, R., Muller, T., Schwarz M., Falkenstein, M., and Beste, C. (2009). Response monitoring in de novo patients with Parkinson's disease. PLoS ONE 4:e4898. doi: 10.1371/journal.pone.0004898

Wittfoth, M., Kustermann, E., Fahle, M., and Herrmann, M. (2008). The influence of response conflict on error processing: evidence from event-related fMRI. Brain Res. 1194, 118-129. doi: 10.1016/j.brainres.2007.11.067

Xiao, Z., Wang, J., Zhang, M., Li, H., Tang, Y., Wang, Y., et al. (2011). Error-related negativity abnormalities in generalized anxiety disorder and obsessive-compulsive disorder. 
Prog. Neuropsychopharmacol. Biol. Psychiatry 35, 265-272. doi: 10.1016/j.pnpbp.2010.11.022

Xing, Q. H., Wu, S. N., Lin, Z. G., Li, H. F., Yang, J. D., Feng, G. Y., et al. (2003). Association analysis of polymorphisms in the upstream region of the human dopamine D4 receptor gene in schizophrenia. Schizophr. Res. 65, 9-14. doi: 10.1016/S09209964(03)00064-1

Yamasue, H., Iwanami, A., Hirayasu, Y., Yamada, H., Abe, O., Kuroki, N., et al. (2004). Localized volume reduction in prefrontal, temporolimbic, and paralimbic regions in schizophrenia: an MRI parcellation study. Psychiatry Res. 131, 195-207. doi: 10.1016/j.pscychresns.2004.05.004

Yan, H., Tian, L., Yan, J., Sun, W., Liu, Q., Zhang, Y. B., et al. (2012). Functional and anatomical connectivity abnormalities in cognitive division of anterior cingulate cortex in schizophrenia. PLoS ONE 7:e45659. doi: 10.1371/journal.pone.0045659

Zald, D. H. (2003). The human amygdala and the emotional evaluation of sensory stimuli. Brain Res. Brain Res. Rev. 41, 88-123. doi: 10.1016/S0165-0173 (02)00248-5
Zirnheld, P. J., Carroll, C. A., Kieffaber, P. D., O'Donnell, B. F., Shekhar, A., and Hetrick, W. P. (2004) Haloperidol impairs learning and error-related negativity in humans. J. Cogn. Neurosci. 16, 1098-1112. doi: $10.1162 / 0898929041502779$

Conflict of Interest Statement: The authors declare that the research was conducted in the absence of any commercial or financial relationships that could be construed as a potential conflict of interest.

Received: 10 January 2013; paper pending published: 05 March 2013; accepted:
18 June 2013; published online: 18 July 2013.

Citation: Manoach DS and Agam Y (2013) Neural markers of errors as endophenotypes in neuropsychiatric disorders. Front. Hum. Neurosci. 7:350. doi 10.3389/fnhum.2013.00350

Copyright (C) 2013 Manoach and Agam. This is an open-access article distributed under the terms of the Creative Commons Attribution License, which permits use, distribution and reproduction in other forums, provided the original authors and source are credited and subject to any copyright notices concerning any third-party graphics etc. 